\title{
Stand-Alone Containment Analysis of the Phébus FPT Tests with the ASTEC and the MELCOR Codes: The FPT-0 Test
}

\author{
Bruno Gonfiotti and Sandro Paci \\ Dipartimento di Ingegneria Civile e Industriale (DICI), University of Pisa, Largo Lucio Lazzarino 2, 56122 Pisa, Italy \\ Correspondence should be addressed to Bruno Gonfiotti; bruno.gonfiotti@for.unipi.it
}

Received 13 May 2017; Accepted 21 August 2017; Published 5 December 2017

Academic Editor: Tomasz Kozlowski

Copyright (C) 2017 Bruno Gonfiotti and Sandro Paci. This is an open access article distributed under the Creative Commons Attribution License, which permits unrestricted use, distribution, and reproduction in any medium, provided the original work is properly cited.

\begin{abstract}
The integral Phébus tests were probably one of the most important experimental campaigns performed to investigate the progression of severe accidents in light water reactors. In these tests, the degradation of a PWR fuel bundle was investigated employing different control rod materials and burn-up levels in strongly or weakly oxidizing conditions. From the results of such tests, numerical codes such as ASTEC and MELCOR have been developed to describe the evolution of a severe accident. After the termination of the experimental Phébus campaign, these two codes were furthermore expanded. Therefore, the aim of the present work is to reanalyze the first Phébus test (FPT-0) employing the updated ASTEC and MELCOR versions to ensure that the new improvements introduced in such codes allow also a better prediction of these Phébus tests. The analysis focuses on the stand-alone containment aspects of this test, and the paper summarizes the main thermal-hydraulic results and presents different sensitivity analyses carried out on the aerosols and fission products behavior. This paper is part of a series of publications covering the four executed Phébus tests employing a solid PWR fuel bundle: FPT-0, FPT-1, FPT-2, and FPT-3.
\end{abstract}

\section{Introduction}

In the last 40 years, several efforts have been carried out to investigate the release of fission products (FPs) from a damaged nuclear core and their subsequent behavior in the primary circuit and the containment system of a nuclear power plant during a severe accident (SA) sequence $[1,2]$. Different experimental campaigns were carried out investigating specific phenomena or the coupling among two or more phenomena, although only the international Phébus experimental program was devoted to the study of a SA in its different phases and aspects, the core degradation, the transport of FPs, and structural materials through the primary system, and finally their release into the containment [3]. This experimental campaign was carried out in the integral Phébus facility at the "Institut de Radioprotection et de Sûreté Nucléaire" (IRSN) laboratories in Cadarache (F). Five integral tests were performed, investigating the main processes affecting the severe degradation of the nuclear fuel and control rods, the release of FPs and control materials, their transport through the reactor coolant circuit, and their deposition as aerosols in the containment vessel [4-6]. Different fuel burn-up levels, control rod materials, and thermal-hydraulic conditions were investigated [7]. The Phébus research program has provided a comprehensive database to improve the understanding of the various phenomena leading to fission product behavior. Furthermore, these experiments are the most representative integral cases, in such a way that this program has formed a valuable validation database for several severe accident codes [8]. This FPT-0 test employs, in detail, a bundle of fresh nuclear fuel with an Ag-In-Cd control rod, under steam-rich conditions [9]. In the present paper, a stand-alone containment analysis of this test is presented, employing the latest release versions of two of the most worldwide employed SA codes: ASTEC v.2.0 revision 3 patch 3 and MELCOR V2.1.6840. Both these integral codes are able to simulate a SA from the initiating event until the release of FPs outside the containment. The aim of the work is to investigate the main parameters influencing the FPs behavior inside the containment during the four main phases of the test (degradation, aerosol, washing, and chemistry phases). Different previous analyses (for the full-plant or the standalone containment) have employed too complex or too coarse 


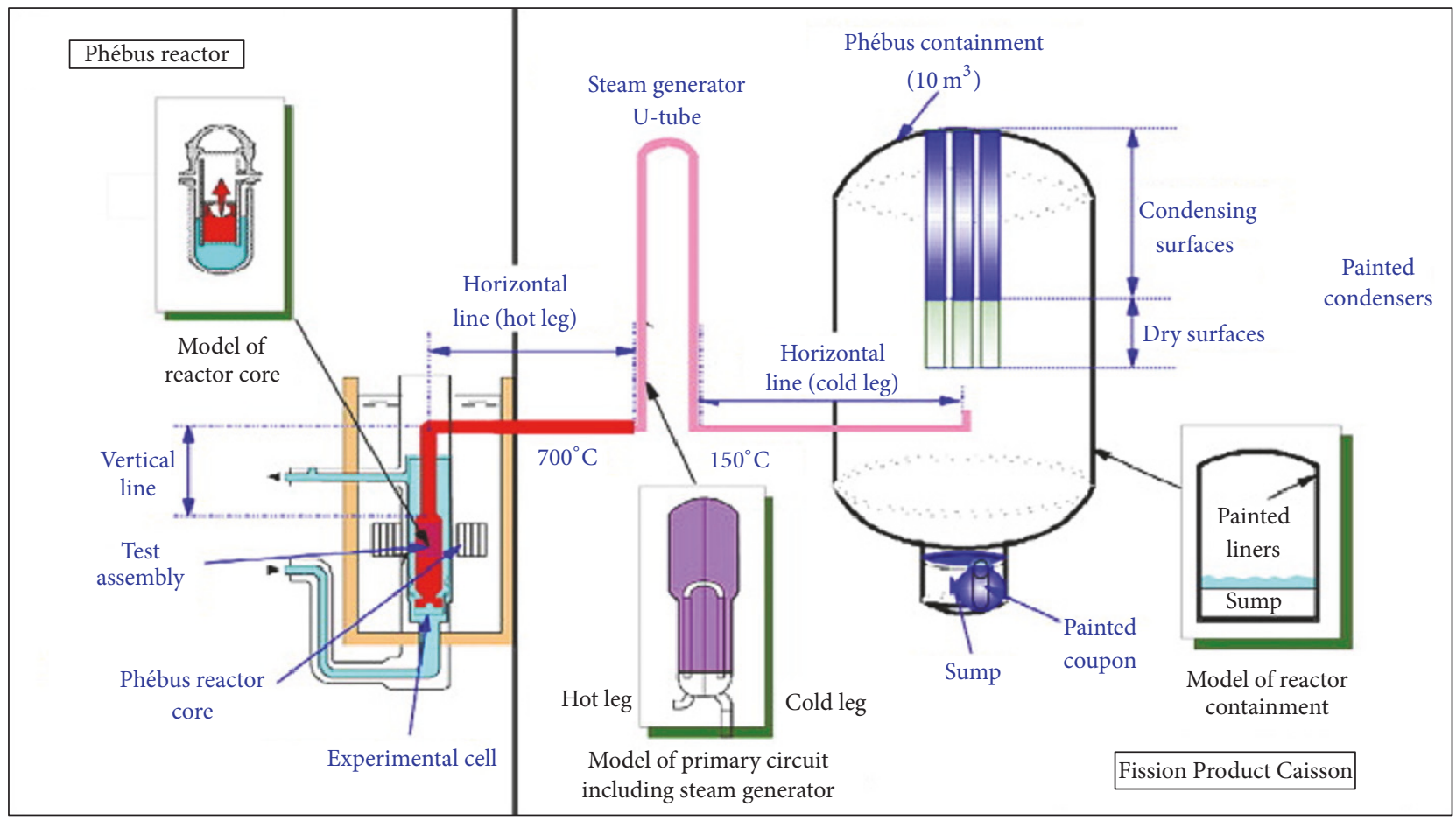

FIgURE 1: Schematic overview of the Phébus facility (original image taken from [3]).

nodalizations [10-15], not able to catch the main thermalhydraulics or aerosol phenomena, or to be employed for full-plant analysis. For this purpose, three different spatial nodalizations of the Phébus containment vessel have been developed to show that too simple nodalizations are not able to simulate the thermal-hydraulic transient. The simplest model consists in 7 control volumes (CVs), 12 heat structures (HSs), and 7 flow paths (FLPs), while the most complex one consists in $21 \mathrm{CVs}, 33 \mathrm{HSs}$, and 32 FLPs. These three nodalizations have been kept as simple as possible (as the number of CVs and HSs) to allow a similar spatial schematization also for full plant analysis. These nodalizations have been also developed in the most identical way possible for both codes, but the different modelling approaches of certain aspects were all exploited to obtain the best possible results with each code. The present paper is a part of a series of publications, covering the 4 Phébus tests executed with a solid PWR fuel bundle: FPT-0, FPT-1, FPT-2, and FPT-3. The aim is to write a detailed paper for each Phébus test, to underline and discuss the main aspects of the containment behavior in the different test's conditions. For this reason, these papers will follow a similar strategy in the closest possible way. An additional paper is also planned to summarize the main findings of these four works, providing also a comparison on the influence of each specific sensitivity parameters investigated on each specific test. Of these five papers, the one covering the FPT1 test has been already published [16]. Observations made during these analyses led to a thorough understanding of the in-containment source term and its coupling with thermalhydraulics under unsaturated but condensing atmospheres.

\section{The Phébus Facility}

The Phébus facility is downscaled to a size of $5000: 1$ of a typical French 900 MWe class pressurized water reactor (PWR). A schematic sketch of the facility is shown in Figure 1 [3]. The first component is the driver core and its cooling circuit, encapsulated inside a cylindrical shroud. The core consists of a PWR fuel bundle, two instrumented fuel rods, and a control rod. Different fuel burnup levels and control rod materials were investigated in each Phébus test. During these tests, the driver core is heated up and irradiated to recreate the temperature increase supposed to occur during a loss of coolant accident (LOCA) and the FPs build-up during normal operations. At the bottom of the shroud a line is installed to inject steam. Different steam injection slopes were investigated in each test to analyze the fuel behavior under strongly or weakly oxidizing conditions. At the top of the shroud, the experimental line (EL) transports steam, incondensable gases, and FPs into the containment. The EL is subdivided into three parts:

(i) the first part, made of Inconel-600, simulates a PWR hot leg;

(ii) the second part, still made of Inconel-600, simulates a U-tube type SG;

(iii) the third part, made of AISI 304L, simulates a PWR cold leg.

Finally, the EL enters into the center of the containment vessel to simulate a cold leg LOCA. 
The containment vessel has a total free volume of $10 \mathrm{~m}^{3}$, with a height of about $5 \mathrm{~m}$ and an inner diameter of about $1.8 \mathrm{~m}$. The containment has a cylindrical shape with a water sump in the lower part. The sump has a height of $0.6 \mathrm{~m}$ and an inner diameter of $0.584 \mathrm{~m}$ to reproduce a representative atmosphere water exchange surface [17]. The top and the bottom parts of the vessel are closed with a semi-ellipsoidal structure. The containment walls are made of AISI 316L, and their temperatures are controlled through two independent systems, respectively, for the sump zone and for the "cylindrical" zone. The aims of the two cooling loops are to decouple the sump water temperature from the gas temperature, and to avoid condensation onto containment walls. A spray system is also inserted in the lower containment zone, to washdown the FPs settled on the bottom vessel surfaces. The spray almost covers the entire flow-through area of the cylindrical containment part, and it is fed only by the water contained in the sump.

Three condensers are attached at the top vault to simulate the cold structures of a reactor building. The main aim of these condensers is to allow the control of the heat transfer and steam condensation. Each condenser has an external diameter of $0.15 \mathrm{~m}$, a height of $2.5 \mathrm{~m}$, and it is subdivided into two parts: the "dry" part of $0.782 \mathrm{~m}$ and the "wet" part of $1.718 \mathrm{~m}$. The total surface area of condensers is about $3.5 \mathrm{~m}^{2}$ : $2.4 \mathrm{~m}^{2}$ for the wet part, and $1.1 \mathrm{~m}^{2}$ for the dry part. The inner temperatures of the two condenser halves are controlled by two independent loops, to allow condensation only onto the wet part. This wet part is also covered with an epoxy paint, to allow the organic iodine formation. Further details on the facility can be found in the final report of the FPT-0 test [9].

\section{The FPT-0 Test and Boundary Conditions}

The Phébus FPT-0 test can be subdivided into four different phases:

(i) The degradation phase, when the driver core is heated up to allow the progressive melting of the fuel and the subsequent release of FPs. This phase starts at $0 \mathrm{~s}$ and ends at 18,138 s. The fuel employed consists in a fresh PWR rod bundle irradiated for a very short period to allow the formation of short-living FPs, with a Ag-In$\mathrm{Cd}$ control rod. The degradation occurs in a strongly oxidizing atmosphere.

(ii) The aerosol phase, with the containment maintained in stable conditions and isolated from the driver core (at 20,438 s). This phase starts at 20,438 s and ends at $86,018 \mathrm{~s}$.

(iii) The washing phase, with the activation of the spray inside the containment, to wash down the FPs settled onto the elliptic bottom. The FPs are then collected inside the sump. This phase starts at 111,218 s and ends at $112,118 \mathrm{~s}$.

(iv) The chemistry phase. During this last phase, no condensation occurs and the iodine chemistry in the sump is analyzed. This phase starts at $133,718 \mathrm{~s}$ and ends at $433,848 \mathrm{~s}$, that is, till the termination of the test.

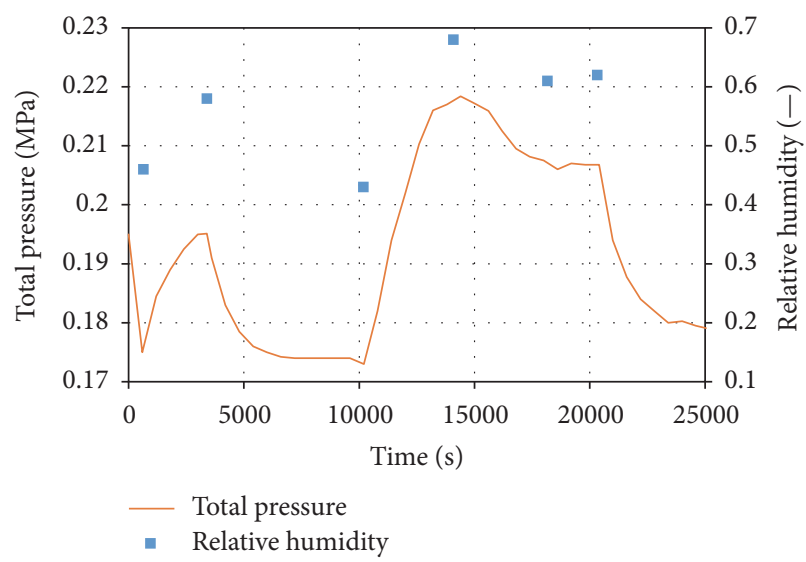

FIgURE 2: Total pressure and r.h. evolutions during the first 25,000 s of the test.

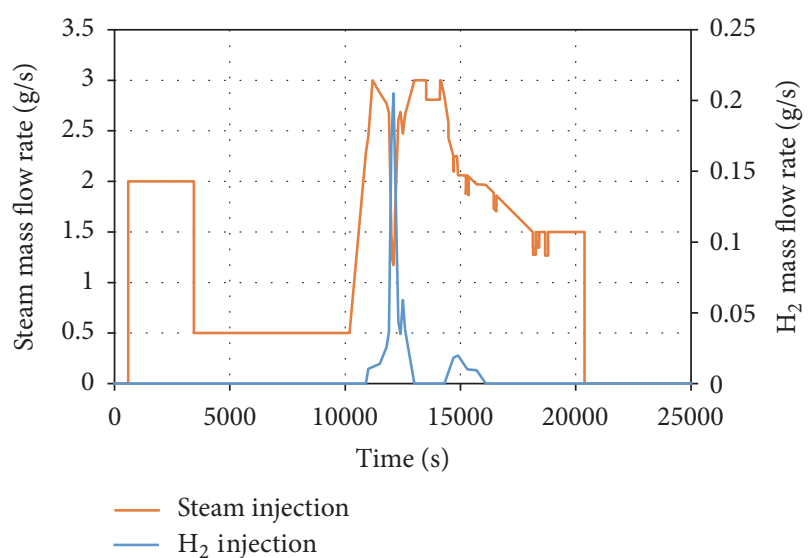

Figure 3: Steam and $\mathrm{H}_{2}$ injection flow rates during the test.

In Figure 2, the containment total pressure and the relative humidity (r.h.) trends during the first 25,000 s of the FPT0 test are shown. The data provided inside the FPT- 0 final report [9] do not cover the entire test, and for the r.h., scarce data points are also reported. During the first 25,000 s, the pressure and the r.h. follow the evolution of the steam flow rate (Figure 3). After the termination of the steam injection, the pressure (Figure 4) remains almost constant until $40,000 \mathrm{~s}$ when the wet condensers' temperature is increased to $383.15 \mathrm{~K}$. This increase lasts until the beginning of the washing phase preparation activities (88,358 s). Such actions consist in an initial decrease of the vessel cylindrical wall temperature followed by a subsequent increase, the decrease of the wet condensers and the sump wall temperatures, and the isolation of the vessel elliptic bottom from the primary organic loops controlling the vessel cylindrical wall temperature (Figure 5). The primary organic loops are closed circuits in which an organic coolant flows. These loops are equipped with heaters and pumps to set the vessel's walls temperatures according to the test schedule. The spray activation triggers an abrupt containment total pressure and 


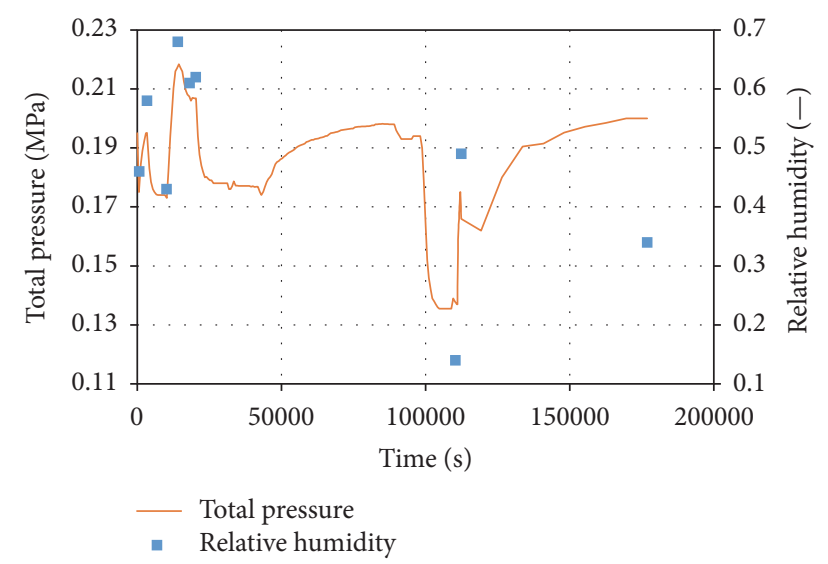

FIGURE 4: Total pressure and r.h. evolutions up to 200,00 s after the beginning of the test.

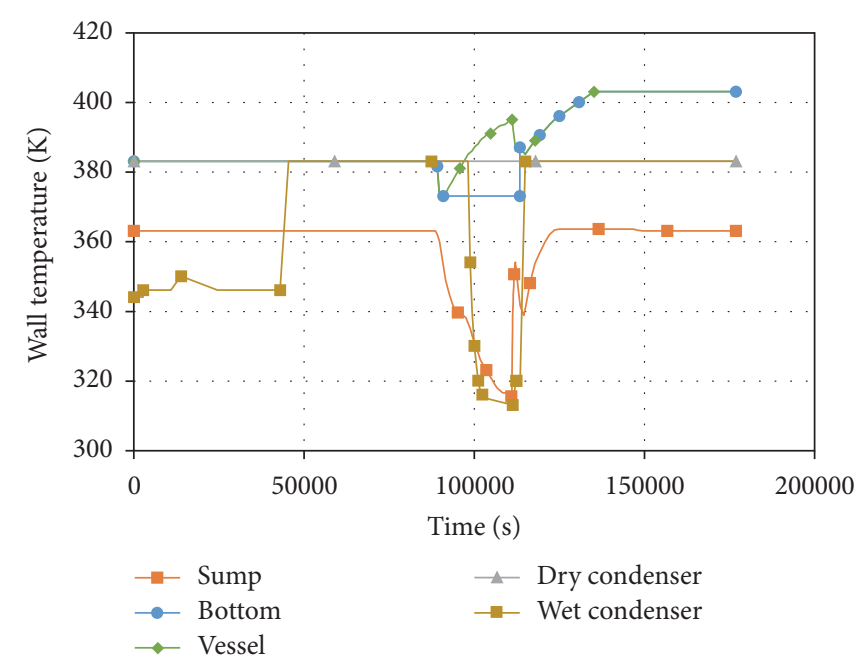

FIGURE 5: Wall temperature evolutions during the first 200,000 s of the test.

r.h. decrease. After the termination of the washing phase, the elliptic bottom is reconnected to the primary organic loop, and the wet condensers and the sump wall temperatures start to increase again for the following chemistry phase. The wall temperatures were all employed as boundary conditions. No experimental data for the total pressure and the wall's temperatures were provided in [9] after 180,000 s. During this last phase (chemistry phase), only the r.h. was measured for three times, at $223,718 \mathrm{~s}$, at $310,118 \mathrm{~s}$, and at $396,518 \mathrm{~s}$. A r.h. value of $30 \%$ was reported for the first two measurements, while a value of $31 \%$ was shown for the third one.

Two main injections occur in the containment during the test: the steam and the $\mathrm{H}_{2}$ injections. The steam is injected at the bottom of the degraded fuel element, but only a fraction flows in the containment due to the steam reaction with the fuel clad. $\mathrm{H}_{2}$ is produced by the Zircaloy oxidation reaction, but in the present paper, such phenomenon is not simulated, so the $\mathrm{H}_{2}$ mass flow rate is imposed as a boundary condition as well as the steam flow rate into the containment (Figure 3). During the test, several samplings are also performed to analyze the composition of the containment atmosphere.

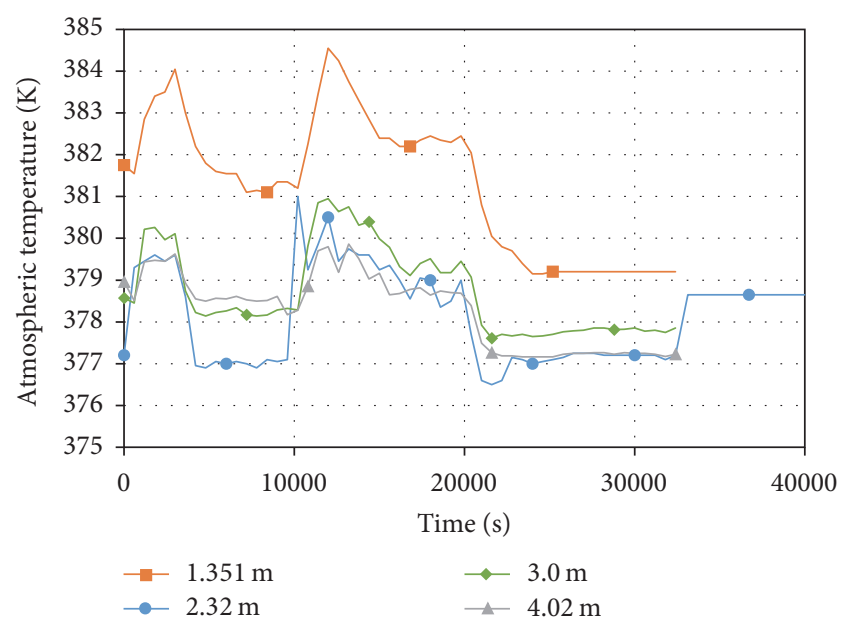

FIGURE 6: Atmospheric temperatures at different containment heights during the fire first $40,000 \mathrm{~s}$ of the test.

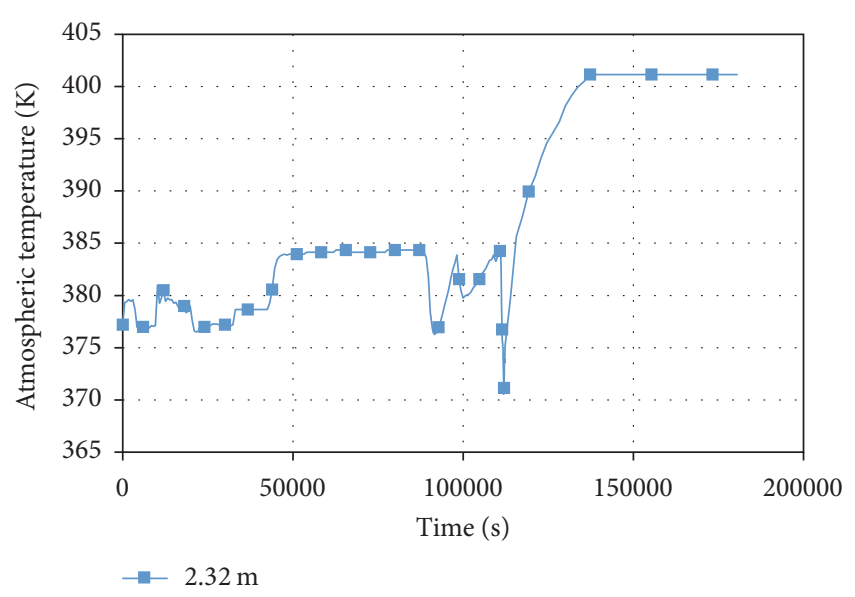

Figure 7: Atmospheric temperature evolution at $2.32 \mathrm{~m}$ up to $200,000 \mathrm{~s}$.

Figure 6 shows the mean atmospheric temperature at different containment heights until 40,000 s, while in Figure 7 the atmospheric temperature at $2.32 \mathrm{~m}$ only until $200,000 \mathrm{~s}$ is reported because no data were provided for the other heights. In Figure 8, the sump water PH evolution for the first $200,000 \mathrm{~s}$ of the test is reported. Again, the data provided for the $\mathrm{PH}$ evolution do not cover the entire test. In Figure 9, the total condensation rate on the wet condensers until 35,000 s is shown (no condensation occurs after that time). Finally, the atmospheric and the sump dose rates' evolutions up to 200,000 s are reported in Figure 10. After 180,000 s, the dose rates in the atmosphere and the sump were measured only at $277,338 \mathrm{~s}$, and values of $0.245 \mathrm{~Gy} / \mathrm{s}$ (atmosphere) and $0.127 \mathrm{~Gy} / \mathrm{s}$ (sump) were reported. A more detailed description of the test can be found in the FPT-0 final report [9].

\section{Codes Employed}

As previously said, two codes have been employed for the present paper: ASTEC v.2.0 revision 3 patch 3 and MELCOR 


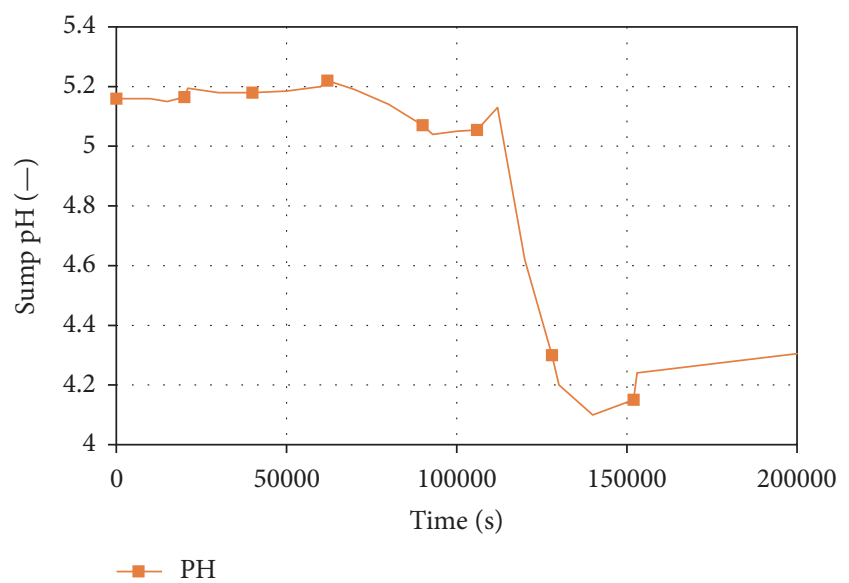

Figure 8: Sump PH evolution for the first 200,000 s of the test.

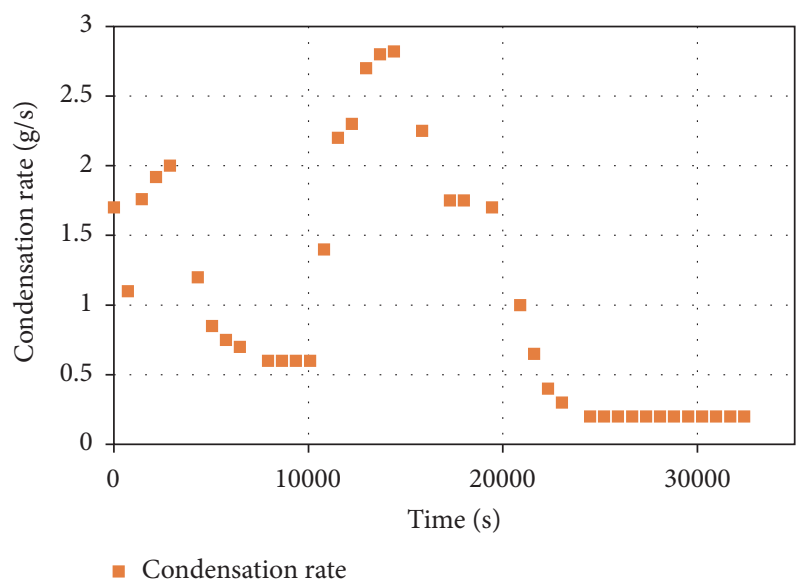

Figure 9: Total condensation rate during the first $40,000 \mathrm{~s}$ of the test.

V2.1.6840. Both codes are capable of simulating a SA from the initiating event to the release of FPs outside the containment. They are based on a lumped-parameter approach, where the spatial domain is subdivided into CVs, connected through FLPs. Inside each CV a nonequilibrium condition is applied for the liquid and gaseous zones. The circulation among the different CVs is provided by the FLPs connecting them. A simplified momentum balance equation is introduced for each FLP, but still capable of catching the main circulation phenomena inside the primary system or the containment. Both codes include also additional packages/modules to couple thermal-hydraulics with aerosol/FP calculations. Significant differences exist regarding the aerosol and FP treatment in terms of models, numerical approach, and coupling with thermal-hydraulics, but such differences will not be discussed in the present paper.

ASTEC is jointly developed by IRSN (France) and GRS (Germany). The code is subdivided into different modules, but in the present work, only the CPA, IODE, and SYSINT modules were employed. The CPA module deals with the containment thermal-hydraulics and aerosol behavior, and it is subdivided into three submodules: THY for thermalhydraulic analysis, AFP for FP behavior, and FIPHOST for FP

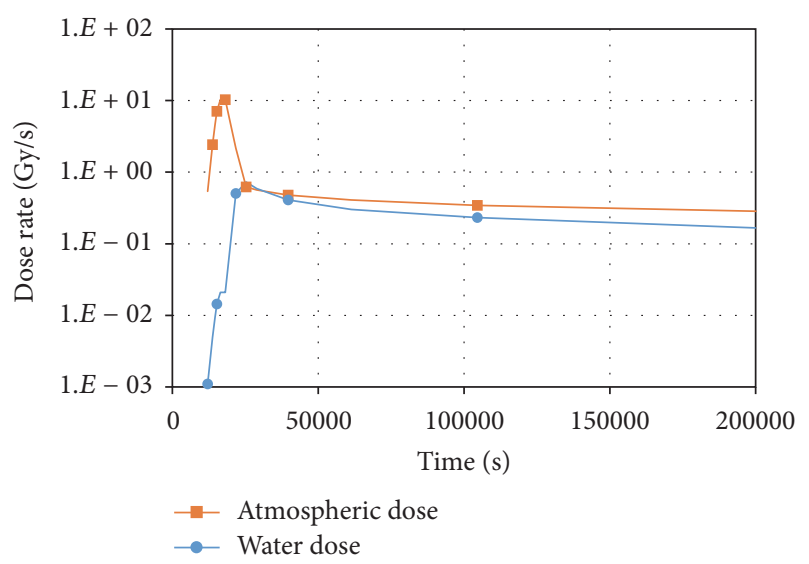

FIGURE 10: Atmospheric and water dose rates in containment during the test.

transport in containment [18]. The IODE module deals with the Iodine and Ruthenium chemistry in containment [19]. Finally, the SYSINT module manages safety systems based on user inputs or plant conditions [20]. Specific information on the different models implemented inside each ASTEC module can be found in the code manuals.

MELCOR is developed by Sandia National Laboratory (USA). The code is subdivided into different packages, but in the present work, only the control function (CF), the control volume hydrodynamic $(\mathrm{CVH})$, the executive (EXEC), the flow path (FL), the heat structure (HS), the material properties (MP), the noncondensible gas (NCG), the radionuclide (RN), the containment spray (SPR), and the tabular function (TF) packages were employed. The CF and TF packages deal with the tabular (TF) and control (CF) functions needed for the correct activation of the other modules. The EXEC package manages the execution parameters of the simulation as time step, beginning and ending simulation time, output files, and so on. The CVH and FL packages model the thermalhydraulic behavior of coolant and incondensable gases. The HS package models the structures attached to the different CVs. The MP and NCG packages activate the structural materials (MP) and the incondensable gases (NCG) needed for the correct execution of the simulations. The SPR package manages the sprays in the containment building. Finally, the RN package models the behavior of aerosols and vapors in the whole plant, from the release from the damaged fuel to the deposition on containment surfaces. This package includes also a specific model to simulate the Iodine behavior in gaseous and liquid phases. Specific information on the different models implemented in each MELCOR module can be found in the code manuals [21].

\section{Employed Nodalizations and Boundary Conditions}

Three spatial nodalizations have been developed to simulate the containment behavior during the FPT-0 test. In Figure 11, a sketch of the three spatial models is shown, and in Tables 1, 2, and 3 the geometrical features and the initial 
TABLE 1: HS’s characteristic lengths.

\begin{tabular}{|c|c|}
\hline Wall & Characteristic length $[\mathrm{m}]$ \\
\hline \multicolumn{2}{|c|}{ Model 1} \\
\hline WSU & 0.146 \\
\hline WB1 & 0.416 \\
\hline W3 & 2.299 \\
\hline W4 & 1.007 \\
\hline W2T & 0.146 \\
\hline W4T & 0.416 \\
\hline WET & 0.15 \\
\hline DRY & 0.15 \\
\hline \multicolumn{2}{|c|}{ Model 2} \\
\hline WSU & 0.146 \\
\hline WB1 & 0.416 \\
\hline W7 & 0.759 \\
\hline W8 & 0.759 \\
\hline W9 & 0.782 \\
\hline W10 & 0.504 \\
\hline W11 & 0.504 \\
\hline W6T & 0.146 \\
\hline W12T & 0.416 \\
\hline WET4 & 0.15 \\
\hline WET5 & 0.15 \\
\hline WET6 & 0.15 \\
\hline DRY & 0.15 \\
\hline \multicolumn{2}{|c|}{ Model 3} \\
\hline WSU & 0.146 \\
\hline WB1 & 0.265 \\
\hline WB2 & 0.142 \\
\hline W13 & 0.759 \\
\hline W14 & 0.759 \\
\hline W15 & 0.782 \\
\hline W16 & 0.504 \\
\hline W17 & 0.504 \\
\hline W6T & 0.146 \\
\hline $\mathrm{W} 12 \mathrm{~T}$ & 0.265 \\
\hline W18T & 0.142 \\
\hline WET4 & 0.15 \\
\hline WET5 & 0.15 \\
\hline WET6 & 0.15 \\
\hline DRY & 0.15 \\
\hline
\end{tabular}

boundary conditions employed for these three models are reported [9]. Identical total pressures $(195 \mathrm{kPa})$ and r.h. (49\%) were employed for the three different nodalizations. The atmospheric and the sump temperatures of each CV were set according to the data coming from the sensors installed at different vessel heights, and the wall temperatures were set according to the boundary conditions shown in Figure 5.

The first scheme (M1) has been employed to show that nodalizations with few nodes are not capable of simulating the thermal-hydraulics transient and the aerosol behavior of
TABLE 2: Spray characteristics.

\begin{tabular}{lc}
\hline Activation time & $111,218 \mathrm{~s}$ \\
Deactivation time & $112,118 \mathrm{~s}$ \\
Droplet diameter & $12 . E-4 \mathrm{~m}$ \\
Mass flow rate & $1.417 E-3 \mathrm{~m}^{3} / \mathrm{s}$ \\
\hline
\end{tabular}

TABLE 3: Thermal-hydraulic sensitivity cases performed.

\begin{tabular}{lc}
\hline Case & Characteristic Length value $[\mathrm{m}]$ \\
\hline 1 & 0.01 \\
2 & 0.015 \\
3 & 0.02 \\
4 & 0.03 \\
5 & 0.04 \\
6 & 0.05 \\
7 & 0.06 \\
8 & 0.07 \\
9 & 0.08 \\
10 & 0.09 \\
11 & 0.1 \\
\hline
\end{tabular}

the FPT- 0 test. This model consists of $6 \mathrm{CV}$ s plus one to simulate the outer environment, 7 FLPs, and 12 HSs.

The CVs cut the main part of the cylindrical vessel in two radial rings, while the CV simulating the sump (SUMP) has a peculiar geometrical shape to avoid a too small gaseous phase when the water level increases to about $0.6 \mathrm{~m}$. A too small sump gaseous phase could lead to a time-step decrease as well as abnormal calculation terminations, due to thermal-hydraulic instabilities (CVs only filled with water cannot be simulated in ASTEC [18]). To avoid this, the CV simulating the sump "enters" for about $0.4 \mathrm{~m}$ into the above vessel bottom zone to have a sufficient gaseous zone in any circumstance. The sump has an initial water inventory of $100 \mathrm{~kg}$, and the gaseous atmosphere is filled with a mixture of $5.25 \%$ of $\mathrm{O}_{2}$ and $94.75 \%$ of $\mathrm{N}_{2}$ in MELCOR (as reported in the FPT-0 final report), and with common air in ASTEC. This small difference has a negligible influence on the overall results obtained as stressed in the following FP sensitivity analyses section. The sump water $\mathrm{PH}$ has been set according to the data reported in the FPT-0 final report [9].

The 7 FLPs connect the different CVs, while the 8 HSs simulate the sump outer wall (WSU), the semi-elliptic bottom, and top of the vessel (WB1, W2T, and W4T), the cylindrical outer wall (W3, W4), and the three condensers (WET and DRY). The four remaining HSs were utilized to provide an aerosol settling structure on the bottom of the $\mathrm{C} 1, \mathrm{C} 2, \mathrm{C} 3$, and $\mathrm{C} 4 \mathrm{CV}$ s as suggested in the MELCOR User's Guide [21]. Except WET and DRY, all these HSs were simulated with an imposed outer temperature evolving in time according to [9], with an inner temperature based on the heat exchange with their surrounding CVs. The characteristic lengths (CLs) were calculated as reported in (1) (the CL is expressed as $L$ in (1)). The first correlation is taken from the CPA theory manual [18] and from a Sandia report on the nodalization of PWR containments [22], while the second is 

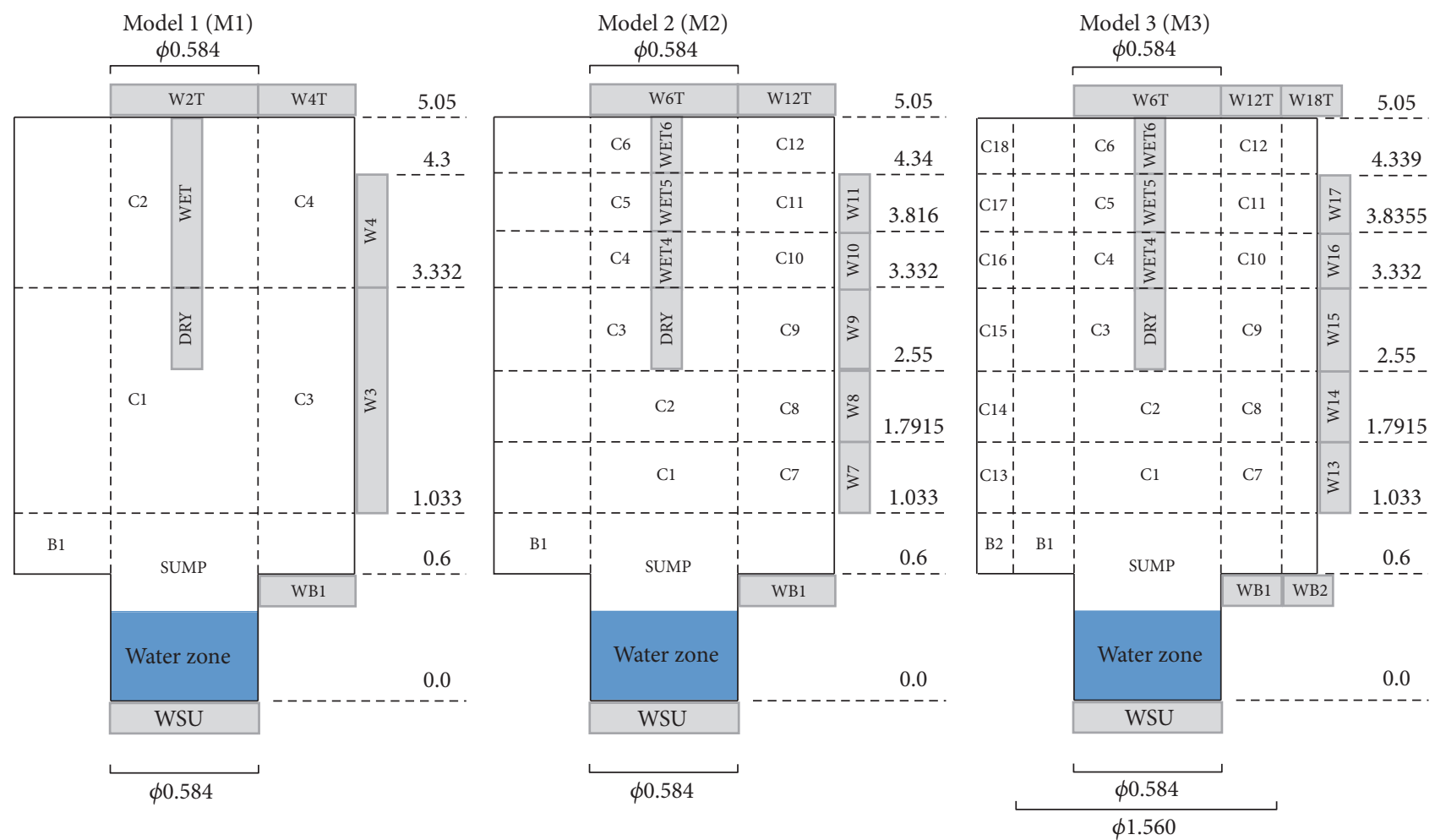

FIGURE 11: Sketch of the nodalizations employed.

taken only from [22] because no information was given in [18].

\section{Characteristic Length Relations}

$$
\begin{gathered}
\text { Vertical cylinders } \longrightarrow L=\text { Height of the wall } \\
\text { Horizontal surfaces } \longrightarrow L=\frac{\text { Area of the wall }}{\text { Perimeter of the wall }}
\end{gathered}
$$

On the opposite, the WET and DRY HSs were simulated with an inner temperature evolving in time according to [9] and with an outer temperature based on the conditions of their surrounding CVs. The characteristic lengths of DRY and WET HSs were set equal to their external diameter $(0.15 \mathrm{~m})$ because such dimension was found capable of predicting a condensation rate closer to the experimental one in all the three models employed. Such discrepancy is due to the film condensation model implemented in both codes, which is not suitable to describe the drop-wise condensation probably occurring on the condenser surfaces. In MELCOR, the issue of CL for a vertically oriented plate type HS was carefully described in [23]. The authors suggest setting the CL value equal to the physical length of the plate but, at the same time, they underline that this solution cannot be extended a priori to other HS's geometries. Even if a detailed investigation on the "CL value" issue similar to that performed in [23] was not performed in the present work, the use of the outer diameter value for a cylindrical wall with condensation on the outer surface can be suggested for MELCOR. For the ASTEC code, similar problems and explanations were also found in
[10], where CL values of about $0.01-0.02 \mathrm{~m}$ were suggested, although, in the present analysis, the values of the same order of magnitude provided too strong condensation rates. On the contrary, a value of about $0.15 \mathrm{~m}$ had shown good condensation rates (see thermal-hydraulics results section). Therefore, the use of a CL value equal to the outer cylinder diameter can be suggested for both codes. This value has also the advantage to be a "real" dimension of the condensers, being the outer condenser diameter. Table 1 presents a summary of the CL values employed.

The solutions proposed in the previous cited work and in this paper stress that the characteristic length of such condensers is still an open question, and so a possible source of user's effect on the calculation. Further studies will be necessary to be able to draw general guidelines about the characteristic lengths of inner walls in a scaled facility.

Additional FLPs and HSs were also introduced in ASTEC and MELCOR to support the thermal-hydraulics and aerosol calculations. In both codes, additional HSs on the bottom of $\mathrm{C}^{*}$ CVs are added to provide a settling surface as suggested in [21]. Such HSs have no influence on the MELCOR calculations, but in ASTEC they improve the overall aerosol results. In ASTEC, three additional FLPs are also added: one to simulate the water draining from the $\mathrm{CV}$ containing the wet condensers into the sump and the other two to simulate the sprays' injection. In MELCOR, two additional HSs are added to simulate the draining into the sump of the water condensed on the wet condenser surfaces. This approach is due to the different draining models implemented in the two codes. ASTEC implements a simple draining model allowing 

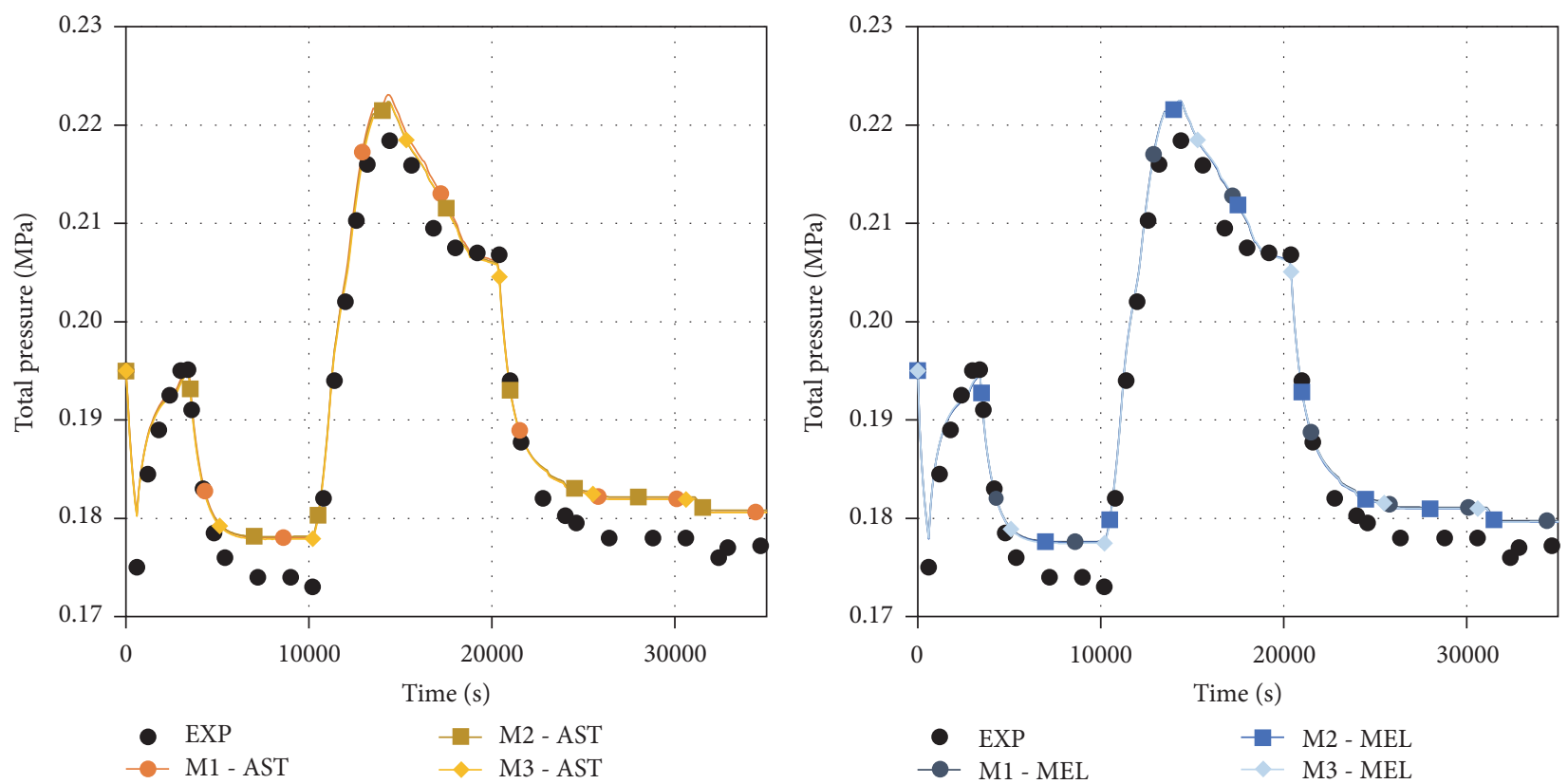

FIGURE 12: Total pressure evolution during the degradation and the early aerosol phases.

the discharge of water accumulated on the bottom of a CV to another CV. On the contrary, MELCOR implements only a model to track the water flow along vertical HSs (the so called "film tracking model") until the ingress in the sump water. In the present work, this last model is applied to simulate the "direct" transport of the condensed water from the bottom of the condenser HS (WET) into the bottom sump HS (WSU). However, this model has not to be employed to simulate the direct transport of water from an upper zone to a lowest zone, but only the water flowing along vertical HSs, although leaving the condensed water on the bottom of the $\mathrm{C} 3 \mathrm{CV}$ would have led to poor thermal-hydraulics results.

In MELCOR, the spray injections are simulated with a specific package instead of atmospheric junctions as in ASTEC. The main spray characteristics are the same for the two codes (Table 2), and a filter has been added in both codes to block aerosols in the sump water.

The steam, $\mathrm{H}_{2}$, and FP injections, as well as the different samplings, were placed in the $\mathrm{ClCV}$ (in all the three models), and their slopes were set according to the data reported in the FPT-0 final report [9]. The whole FP injections were simulated with an aerosol mass media diameter (AMMD) of $1.3 E-6 \mathrm{~m}$ and a geometric standard deviation (GSD) of 2.15. The dose rate evolutions in atmosphere and in the sump have been imposed basing on the data reported in the FPT- 0 final report [9].

The second spatial scheme (M2) is a more refined one, and it is partially able to reproduce the different phenomena occurring during the FPT-0 test. The model consists of 14 CVs plus one for the outer environment, 19 FLPs, and 25 HSs. The spatial subdivision of the vessel is more refined, but the vessel cylindrical zone is still subdivided only into two radial rings. As for the previous M1 scheme, additional HSs and FPs have been introduced in the model to simulate the spray injection, the draining of the condensed water onto wet condenser surfaces, and to support the aerosols and FPs calculations. In ASTEC, five FLPs are schematized: three FLPs to simulate the draining of water from the bottom of the $\mathrm{CV}$ containing the wet condenser surfaces into the sump, and the other two to simulate the spray injection. In MELCOR, the water draining from the upper HS (WET6) to the lower HSs (WET5 and WET4) is correctly simulated, but the direct transport of water from the upper zone (C4) into the sump is still simulated as in M1. All other assumptions made for M1 are also valid for $\mathrm{M} 2$.

The third scheme (M3) is the most complex, and it is capable of correctly catching the main phenomena occurring in the containment vessel during the FPT-0 test. In this model, the vessel cylindrical zone is subdivided into three radial rings, and it consists in $21 \mathrm{CVs}$ plus one for the outer environment, 32 FLPs, and 33 HSs. As for M1 and M2 schemes, additional FLPs and HSs are added to simulate the spray injection, the draining of the condensed water onto wet condenser surfaces, and to support the aerosols and FPs calculations. The remarks made for M1 and M2 are also valid for this model.

\section{Thermal-Hydraulics Results}

The correctness of the thermal-hydraulics predictions is of major importance, because of its influence on the overall aerosols and FPs behavior, especially on the iodine chemistry.

The total pressure evolution inside the containment vessel is shown in Figures 12,13, and 14. During the degradation phase (Figure 12), the maximum discrepancy shown is always below $0.005 \mathrm{MPa}$ for both codes, but major discrepancies start to appear in the following phases. The increase of the wet condensers temperature from $73^{\circ} \mathrm{C}$ to $100^{\circ} \mathrm{C}$ is the main 

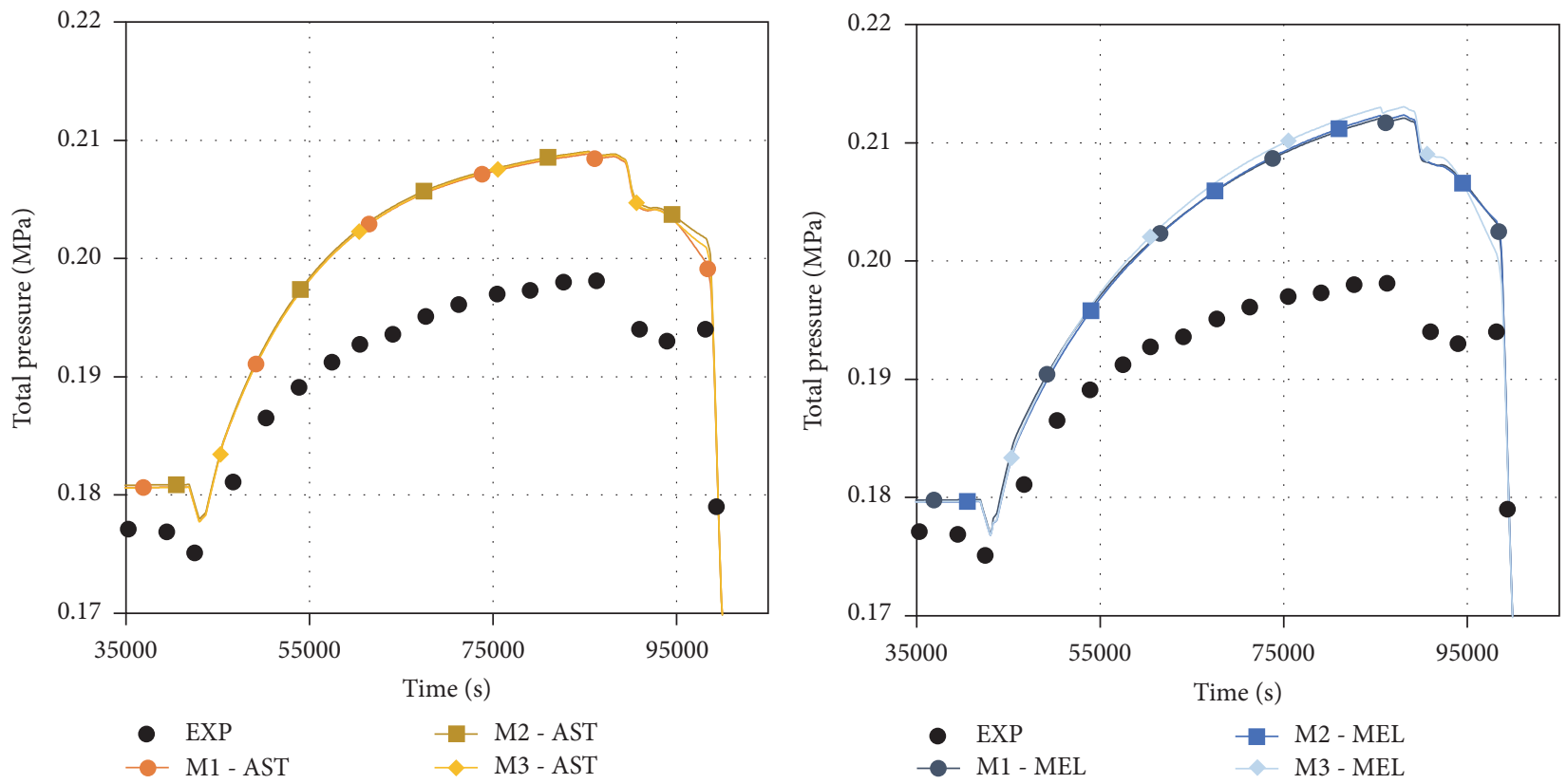

FIGURE 13: Total pressure evolution during the aerosol phase.
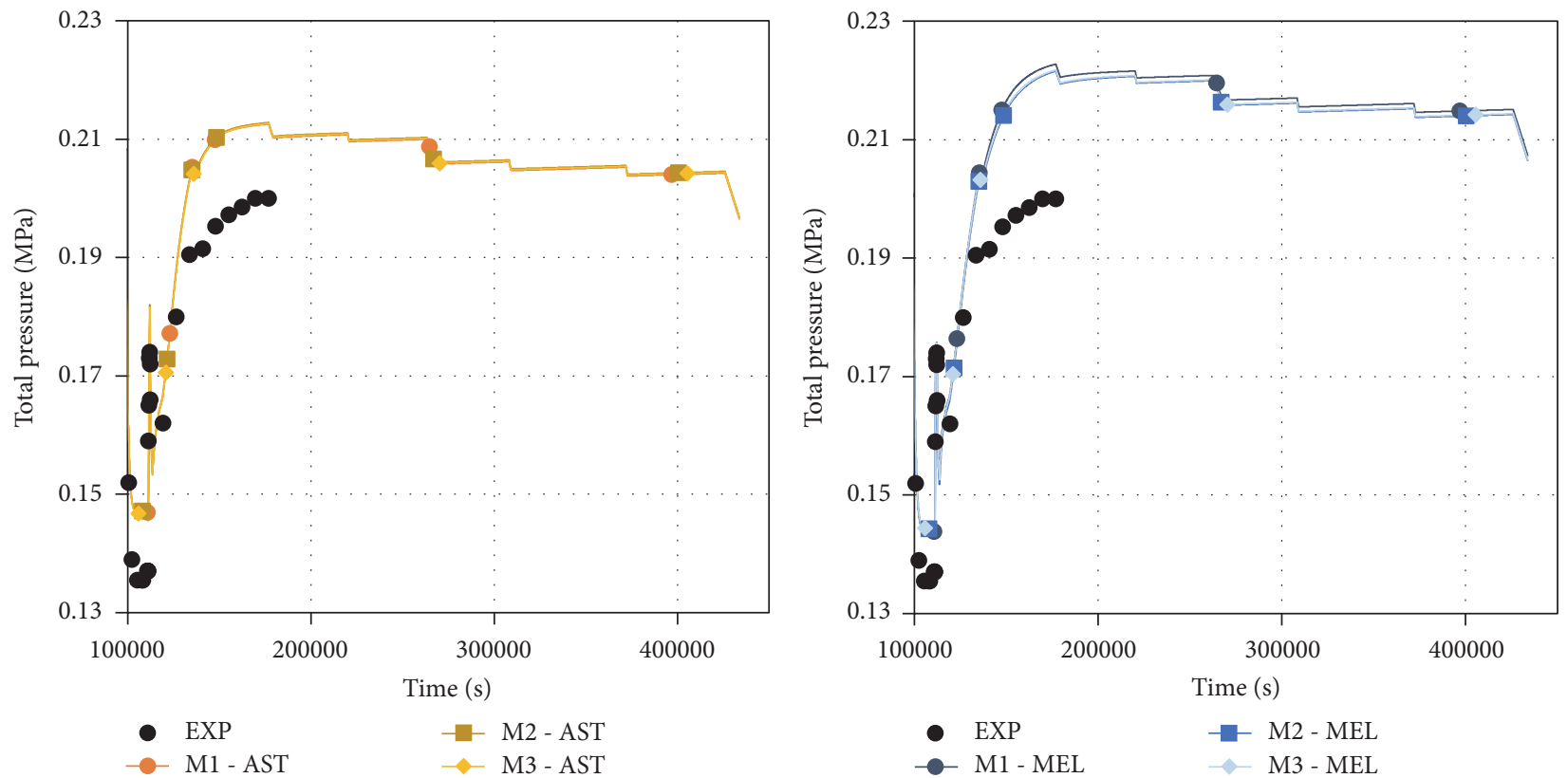

FIGURE 14: Total pressure evolution during the washing and the chemistry phases.

event occurring between 35,000 s and 90,000 s (Figure 5). This action leads to a total pressure increase from about $0.177 \mathrm{MPa}$ to about $0.195 \mathrm{MPa}$ (Figure 13), but the two codes fail to correctly catch this increase, overestimating the total pressure at 90,000 s of about $0.015 \mathrm{MPa}$. Minor differences exist between the predictions of the two codes; hence the spatial nodalization employed may be the cause behind this discrepancy. From 90,000 s to 100,000 s different actions were performed: the wall temperatures were increased from $100^{\circ} \mathrm{C}$ to $130^{\circ} \mathrm{C}$, the wet condensers' temperature was decreased to $40^{\circ} \mathrm{C}$, and the containment elliption bottom was isolated from the loop controlling its temperature. During this time interval, both codes again fail to catch the experimental total pressure trend, probably because of an improper estimation of the influence of these different actions. During the experiment, the vessel temperature increase seems capable of maintaining an almost constant pressure in the containment vessel even if the wet condensers temperature starts to 

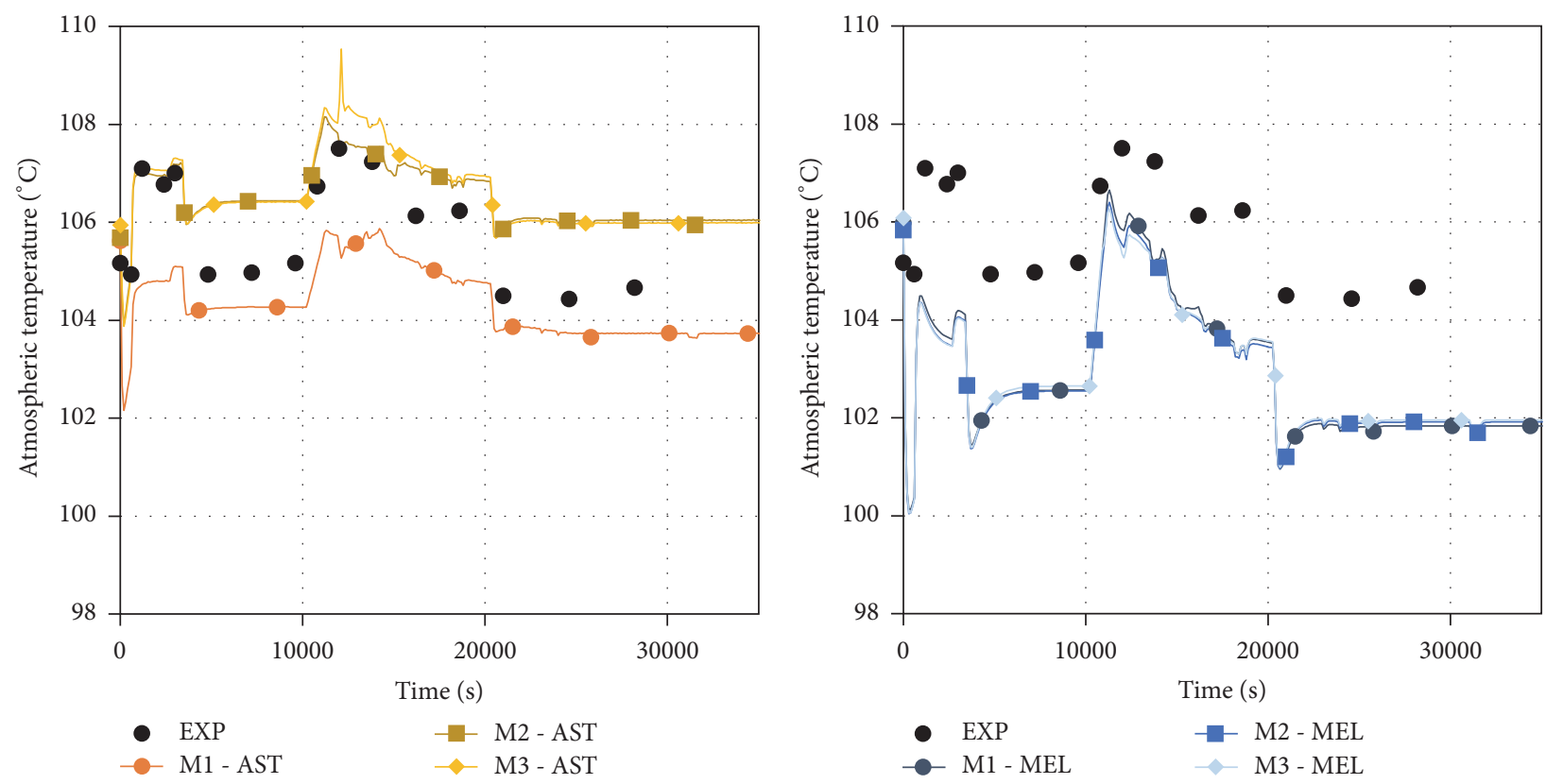

FIgURE 15: Atmospheric temperature evolution at $2.32 \mathrm{~m}$ during the degradation phase.

decrease. On the contrary, in both codes, the vessel wall temperature increase seems insufficient to maintain a stable condition inside the containment vessel and hence the total pressure starts to decrease. This difference is due to the combined effects of the performed nodalization choices and of the code's capabilities. Since similar discrepancies are shown by both codes, a common cause should lie behind them, that is, the employed nodalization. At the same time, preliminary analyses with newer code's versions showed important differences between the ASTEC and the MELCOR codes [24]. Moreover, imprecise information was reported in the FPT-0 final report [9] in this time window. During the isolation period (from 90,938 s to $112,418 \mathrm{~s}$ ), no temperature data were provided for the bottom wall temperature evolution; thus a constant temperature $\left(100^{\circ} \mathrm{C}\right)$ was then assumed. This assumption surely introduces a nonnegligible user effect on the calculations, but the absence of experimental data forces this strategy.

During the washing phase up to $140,000 \mathrm{~s}$, the calculated total pressure trends agree with the experimental one, but a maximum error of about 0.01 MPa still exists (Figure 14). In the following late chemistry phase (after 140,000 s) some discrepancies start to appear again, leading to a total pressure overestimation of about $0.01 \mathrm{MPa}$ in ASTEC and $0.02 \mathrm{MPa}$ in MELCOR. No experimental data were provided into the FPT0 Final Report after 175,000s [9]. Similar discrepancies are shown during the aerosol and the chemistry phases probably because similar actions are performed in these two phases (increase in the wet condenser temperature).

The atmospheric temperature evolutions during the degradation phase at $2.32 \mathrm{~m}, 3.0 \mathrm{~m}$, and $4.02 \mathrm{~m}$ are shown in Figures 15, 16, and 17, respectively. At $2.32 \mathrm{~m}$ and $3.0 \mathrm{~m}$ in ASTEC, a maximum error of about $2^{\circ} \mathrm{C}$ is shown, while at $4.02 \mathrm{~m}$, the error increases to about $4^{\circ} \mathrm{C}$. Such values are almost comparable with the ones from other precedent works by different authors $[12,13]$. On the contrary, in MELCOR at $2.32 \mathrm{~m}$ and $3.0 \mathrm{~m}$, a maximum error of $3.5-4^{\circ} \mathrm{C}$ is shown, while at $4.02 \mathrm{~m}$, the error decreases to about $1.5^{\circ} \mathrm{C}$.

During the following phases, the temperature experimental data were provided only at $2.32 \mathrm{~m}$ (Figure 18). ASTEC shows quite good results, except from $111,000 \mathrm{~s}$ to $115,000 \mathrm{~s}$ when the temperature decreases to about $90^{\circ} \mathrm{C}$. During the other phases, the maximum error does not exceed $2.5^{\circ} \mathrm{C}$. On the contrary, MELCOR predicts quite poor results, especially around $100,000 \mathrm{~s}$ when the atmospheric temperature is underestimated of about $10^{\circ} \mathrm{C}$. The poor results shown by the MELCOR code had pushed to a thorough sensitivity analysis, presented in the following thermal-hydraulics sensitivity analyses section.

In Figure 19, the relative humidity (r.h.) evolution during the degradation phase is reported. Few experimental data points were provided, but sufficient to highlight the evolution of the r.h. during the variation of the steam injection. For MELCOR, the atmospheric temperatures are mainly underestimated, so a r.h. slightly above the experimental values is reported, although the values obtained are quite consistent with the experimental ones, especially employing the M2 and M3 models. For ASTEC, the atmospheric temperatures are mainly underestimated for the M1 model and overestimated for the remaining two models. The r.h. predictions seem not to be influenced by these different predictions, and similar r.h. values are shown during the first 35,000 s of the test. This result is probably due to a code's effect, since no physical reasons can be found to explain it. A maximum error of about $10 \%$ is shown at $20,500 \mathrm{~s}$. This discrepancy is quite high and cannot be considered fully acceptable, but it should also be noticed that it is shown for less than 2,000 s. 

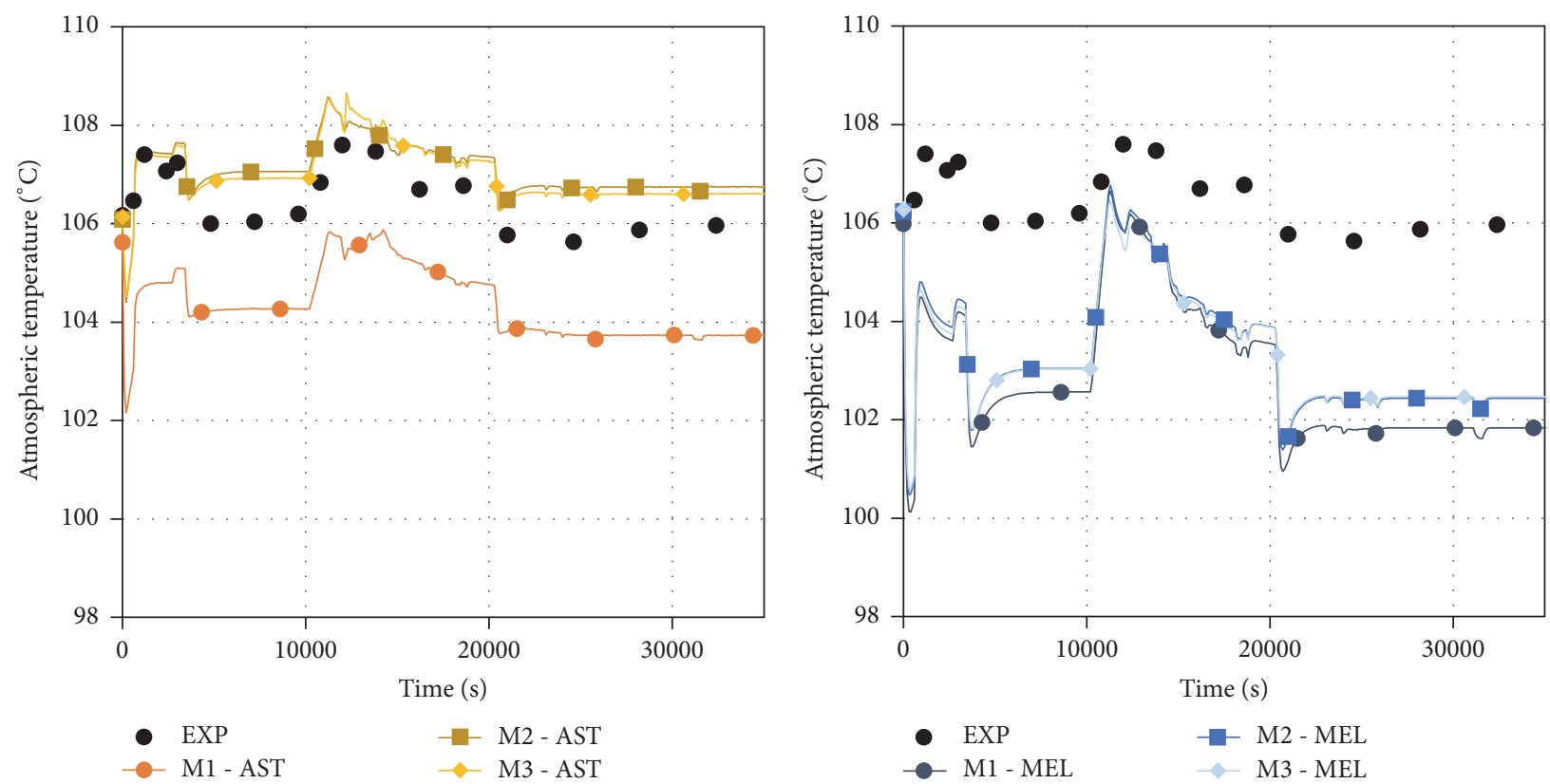

FIGURE 16: Atmospheric temperature evolution at $3.0 \mathrm{~m}$ during the degradation phase.
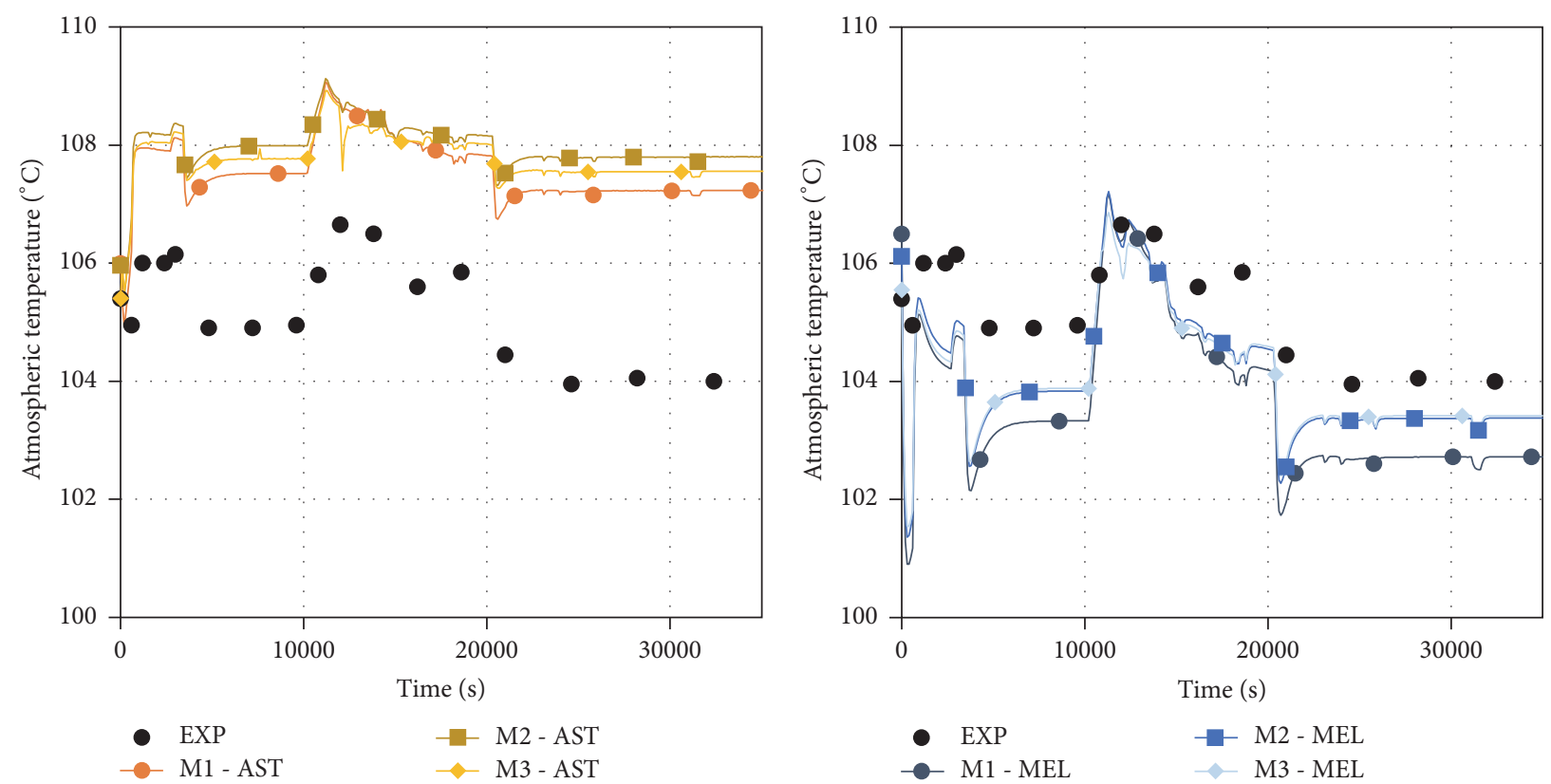

FIGURE 17: Atmospheric temperature evolution at $4.02 \mathrm{~m}$ during the degradation phase.

During the washing phase only two experimental data points for the r.h. were provided (Figure 20). In this case, the lack of experimental data does not allow a careful estimation of the results obtained with both codes. On the contrary, during the chemistry phases, four experimental data points were provided. ASTEC shows quite good results thanks to the good atmospheric temperature prediction shown in Figure 18, while MELCOR overestimates the r.h. of about 7$8 \%$ because the atmospheric temperature was not perfectly matched during this period (Figure 18). Finally, in Figure 21, the condensation rate onto the wet condensers is reported. No appreciable difference can be highlighted among the experimental values and the code predictions.

Anyway, very few differences characterized the results obtained with the three models employing both codes. Considering only the thermal-hydraulic point of view, the simpler model (M1) can be considered the best choice thanks to the lower computation time needed to perform a calculation. 

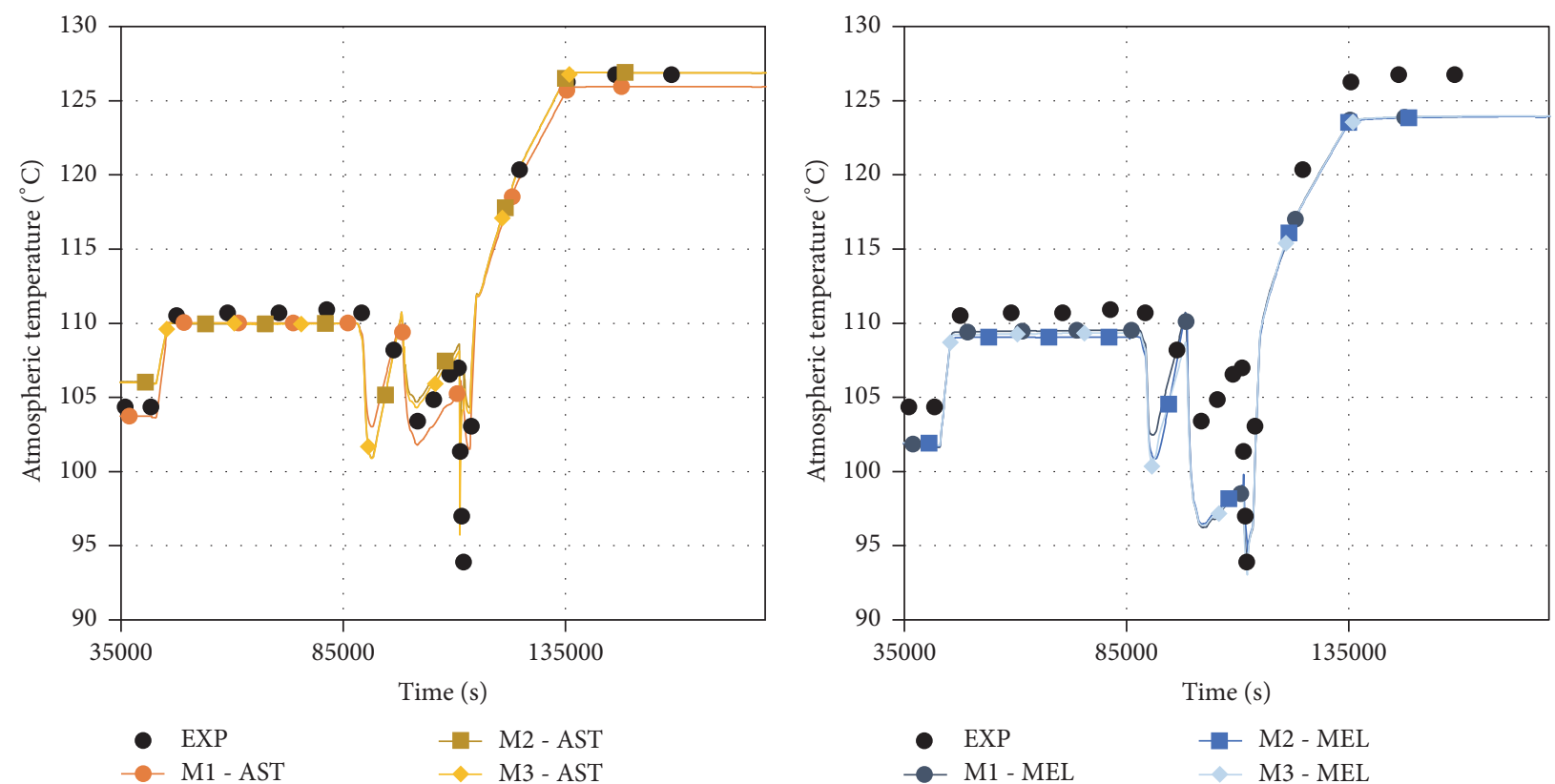

FIgURE 18: Atmospheric temperature evolution at $2.32 \mathrm{~m}$ until 180,000 s.
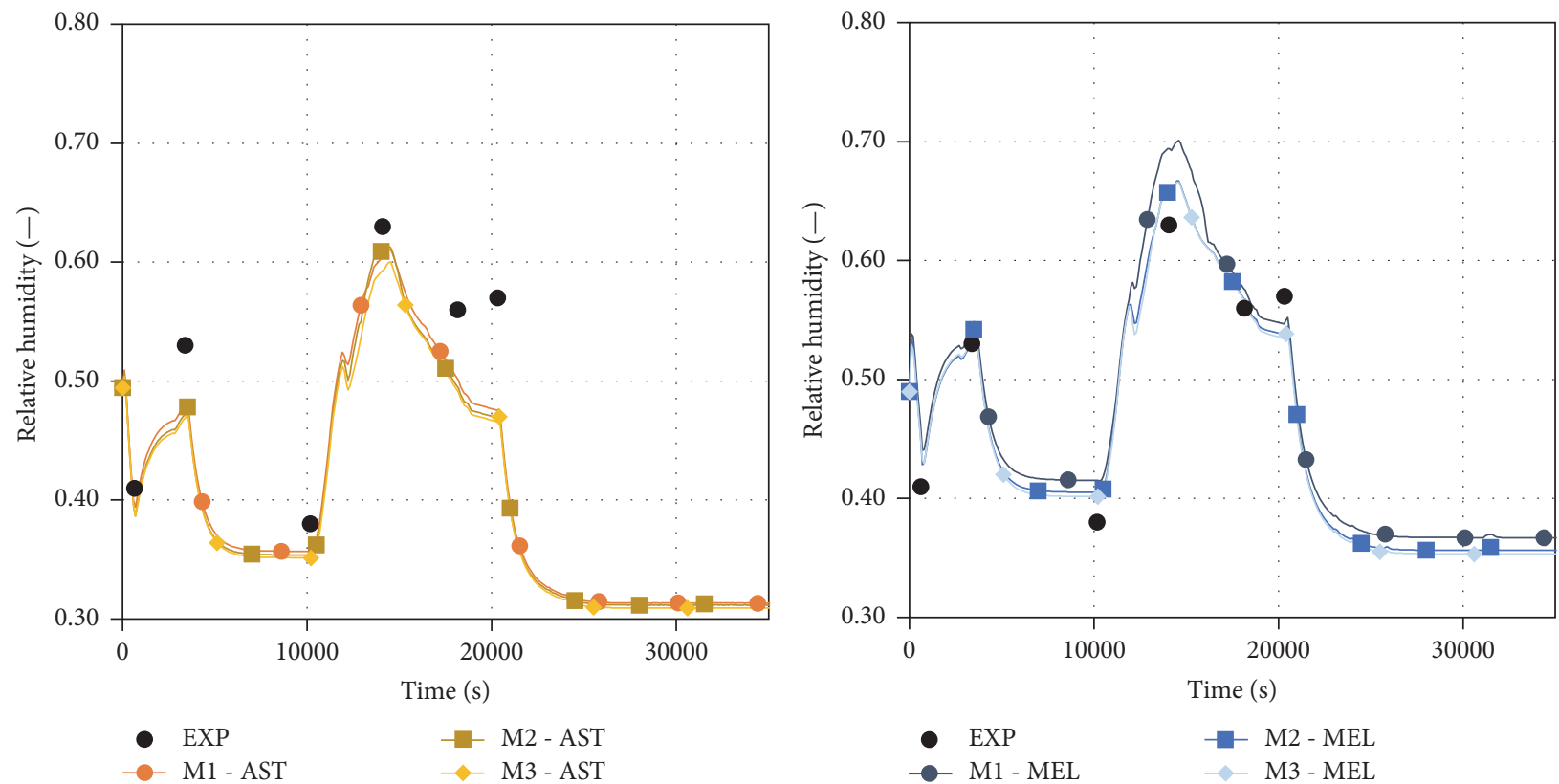

FIGURE 19: Relative humidity evolution during the degradation phase.

However, similar thermal-hydraulics results did not mean that the three models work in the same way and that the internal atmosphere circulation is correctly reproduced.

\section{Thermal-Hydraulics Sensitivity Analyses}

The poor atmospheric temperatures predicted by MELCOR during the washing phase had led to a thorough sensitivity analysis to improve the test predictions. On the contrary, such analysis was not carried out for ASTEC because a good agreement with the experimental data was obtained. Different input parameters have been investigated, but only the characteristic lengths of the outer vessel surfaces were found to be the main influencing parameter. For this purpose, a careful analysis was carried out to find the value of the characteristic length providing the best-estimation of the thermal-hydraulic transient. This analysis has been carried out substituting the characteristic length values calculated for the different outer wall structures (the characteristic lengths for the wet and dry condenser structures were not modified) 

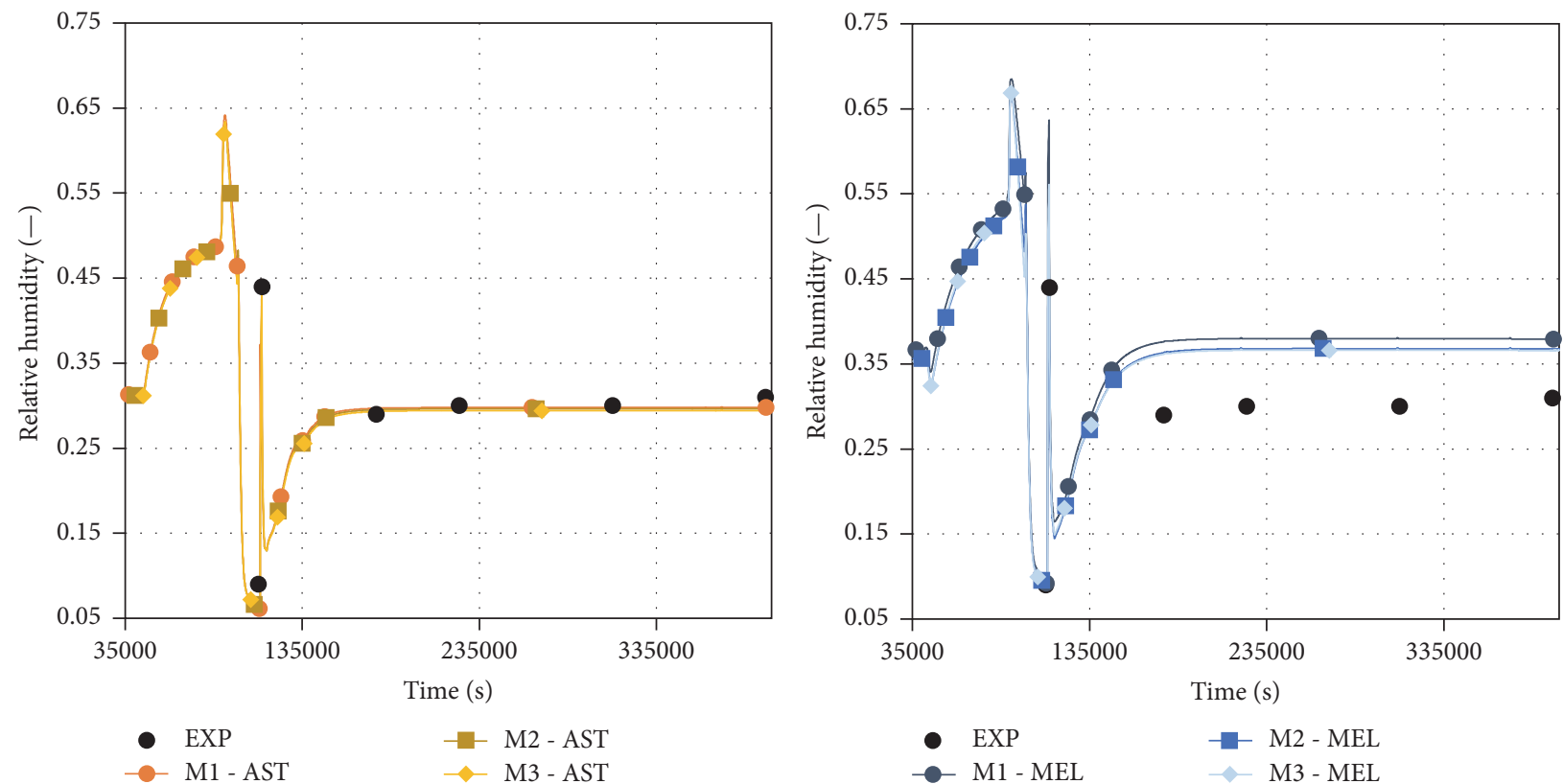

FIGURE 20: Relative humidity evolution during the aerosol, washing, and chemistry phases.
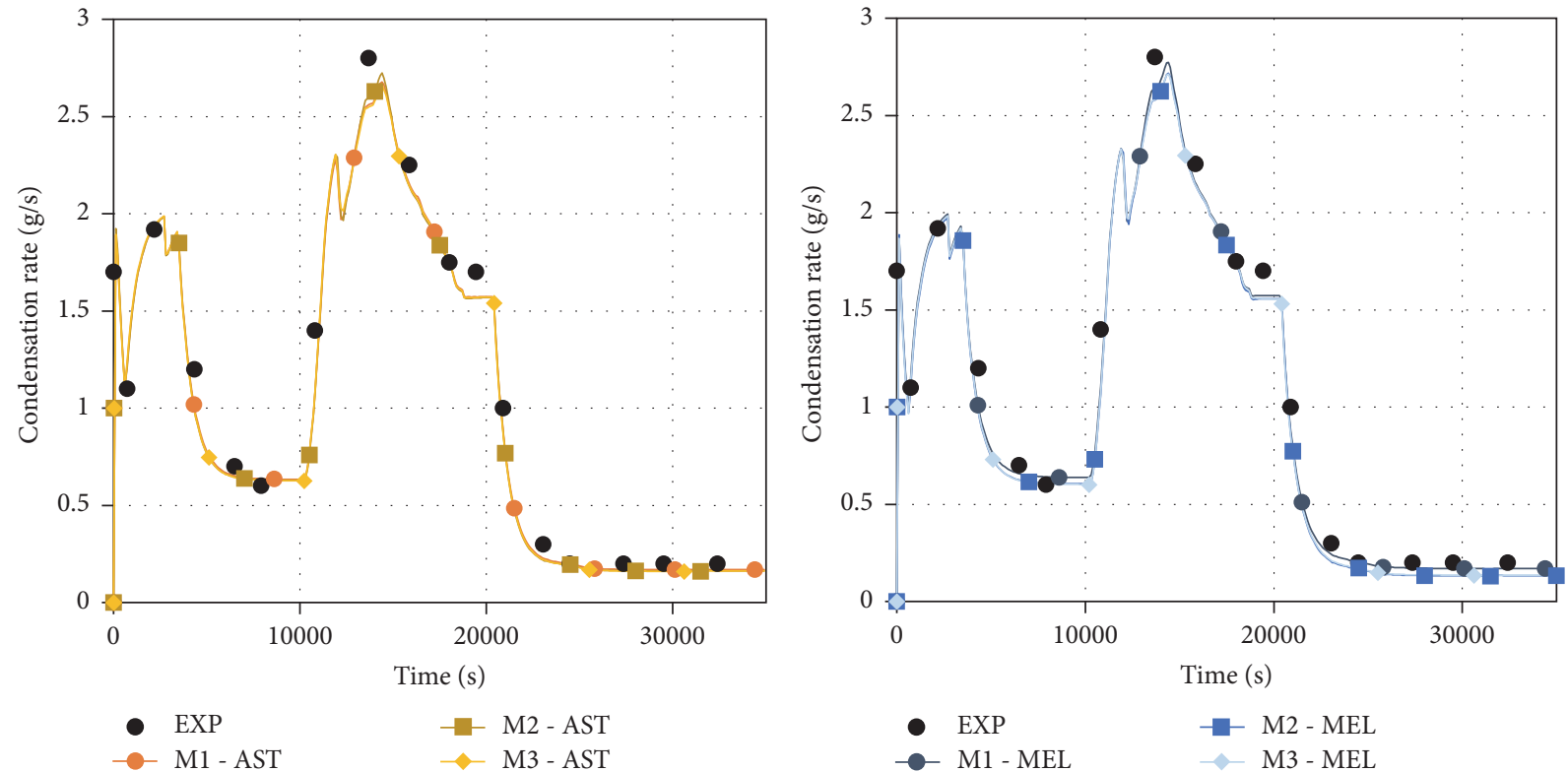

FIGURE 21: Condensation rate on wet condensers during the degradation phase.

with values spanning from $0.01 \mathrm{~m}$ to $0.1 \mathrm{~m}$. A common value was set for each outer vessel structure and a summary of the cases executed is shown in Table 3.

The three spatial nodalizations have shown different values for the best-estimate characteristic length: $0.015 \mathrm{~m}$ provided exhaustive results in M1, $0.01 \mathrm{~m}$ in $\mathrm{M} 2$, and $0.04 \mathrm{~m}$ in M3. A clear indication of the cause behind this behavior cannot be drawn with only three spatial nodalizations. The main difference between M1 and M2 is the improved vertical subdivision of the containment vessel, but the effects of this enhancement seem almost negligible for the characteristic length best-estimation value. On the contrary, the radial subdivision of the vessel seems more influencing. For this purpose, an additional spatial model (M4) was created, subdividing the containment vessel into three radial rings (the $\mathrm{B} 2, \mathrm{C} 13, \mathrm{C} 14, \mathrm{C} 15, \mathrm{C16}, \mathrm{C17}$, and $\mathrm{C} 18$ control volumes of $\mathrm{M} 3$ were each split into two independent CVs). With this new nodalization the best estimation characteristic length was found to be $0.05 \mathrm{~m}$. The obtained improvement is almost similar to that obtained between M1 and M2, so probably a combined effect of increased vertical layers and radial rings subdivision is necessary to increase the characteristic length 


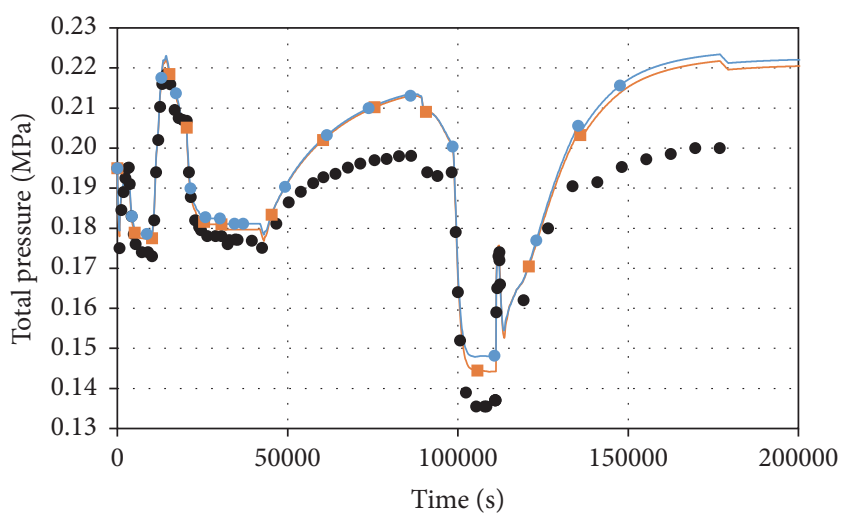

- EXP

$\rightarrow$ M3 default

$\rightarrow$ M3 BE

FIgURE 22: Differences in the total pressure evolution among the MELCOR M3 default and BE cases.

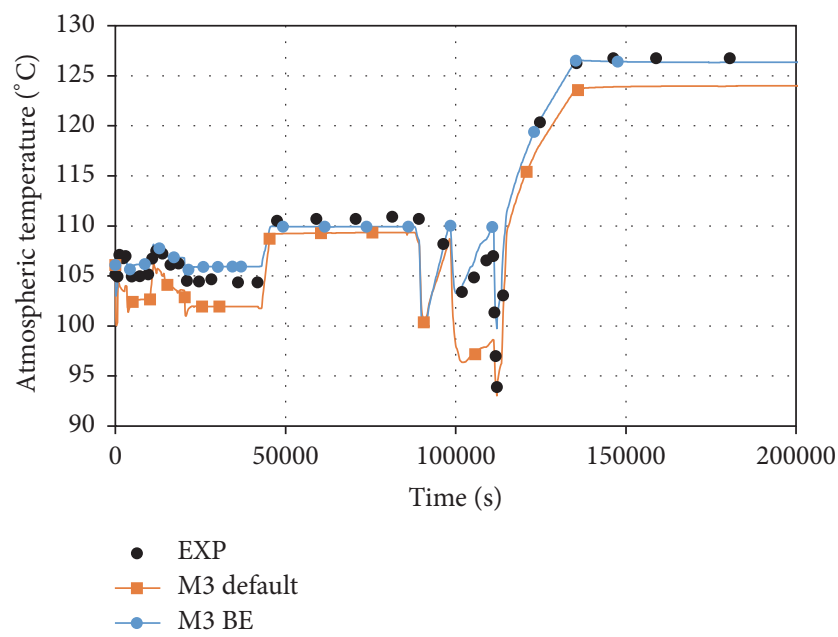

FIGURE 23: Differences in the atmospheric temperature evolution at $2.32 \mathrm{~m}$ among the MELCOR M3 default and BE cases.

values closer to the ones calculated with equation (1) and reported in Table 1. In Figures 22, 23, and 24, the effect of the improved characteristic length value on the total pressure, the atmospheric temperature at $2.32 \mathrm{~m}$, and the r.h. for the M3 model is reported. The total pressure predictions suffer the same uncertainties of the default case, especially between $90,000 \mathrm{~s}$ and $100,000 \mathrm{~s}$. On the contrary, the atmospheric temperature and the r.h. during the aerosol, washing, and chemistry phases are now closer to the experimental values. The influence of these improvements on the aerosols and fission products behavior will be discussed in the following sections.

The conclusions that can be drawn from this sensitivity analysis agree with those reported in [23] where the use of a CL value for a vertical plate-type HS equal to its real height was suggested for a good estimation of the condensation rate, also if underpredicted heat transfer coefficients were still reported, although for other HS's geometries no investigations were reported in [23], and a clear advice that the

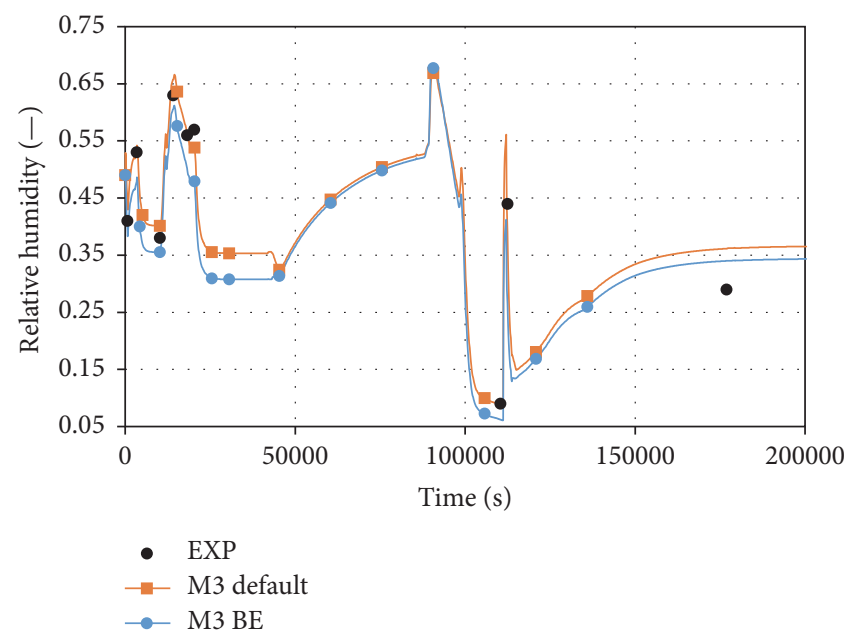

FIGURE 24: Differences in the relative humidity among the MELCOR M3 default and BE cases.

conclusions found may be not valid for other HS's geometries was made.

Under some points of view, the present paper supports these conclusions, even if only an investigation on the heat transfer coefficient was carried out (the condensation behavior was not studied because no condensation occurs in the considered hot HSs). Vertically oriented cylindrical HSs were considered instead of vertical-plate HSs. From the performed analysis, a CL value of few $\mathrm{cm}$ was deemed necessary to better reproduce the thermal-hydraulic transient of the Phébus FPT-0 test. As stated in the MELCOR manual [21], the heat transfer regime is defined based on the ratio between the Reynolds (Re) and the Grashof (Gr) numbers. When the ratio $\mathrm{Re}^{2} / \mathrm{Gr}$ is below 1, a natural convection regime is considered, and if above 10, a forced convection regime is established, and an intermediate condition is considered in between. Considering the Re and Gr number's correlations ( (2) and (3)-in both equations the CL is expressed as $L$ ), it can be easily noticed that both depend on the CL, but with a different magnitude: the Re number with a linear dependency, and the Gr number with a cubic-power dependency.

Reynolds Number

$$
\operatorname{Re}=\frac{\rho \cdot v \cdot L}{\mu}
$$

Grashof Number

$$
\mathrm{Gr}=\frac{g \cdot \beta \cdot\left(T_{s}-T_{\infty}\right) L^{3}}{v^{2}}
$$

This means that-keeping constant all the other parameters-the Gr decreases faster than the Re if lower $\mathrm{CL}$ values are employed. Thus, the ratio $\mathrm{Re}^{2} / \mathrm{Gr}$ will increase as the considered CL value decreases, meaning that the thermal-hydraulics conditions will move from a full natural convective regime to an intermediate or even to a full forced convection regime. Because of this, the calculated heat 


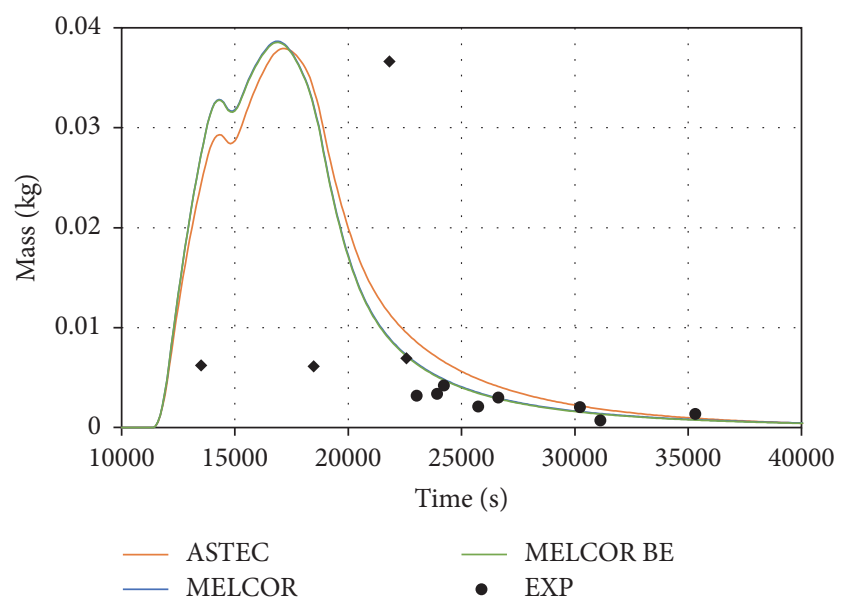

FIGURE 25: Suspended aerosol mass.

transfer coefficient will increase as the employed CL value decreases. Therefore, this decrease of the CL value can be considered an effective way to increase the heat transfer coefficient predicted by MELCOR.

\section{Aerosols and Fission Products Results}

As stated in the thermal-hydraulics results section, only minor differences are shown among the results obtained with the employed spatial nodalizations. Therefore, the aerosols and FPs behaviors have been preliminarily investigated employing the three different models. From this preliminary analysis, it was found that only the third spatial nodalization (M3) is able to correctly predict the coupling between the thermal-hydraulics transient and the aerosols and FPs behavior. For this reason, in the following only the results obtained with the M3 model will be discussed. All the chemical elements reaching the containment vessel-as reported in the final report [9]-have been simulated, but the following discussion will focus only on the main FPs and on structural materials.

In Figure 25, the aerosol mass suspended in the containment atmosphere is reported. During the first $23,000 \mathrm{~s}$, only four experimental data points were provided in [9]. The number of these points-highlighted in the graph with black " " marks-is too scarce to closely follow the real evolution of the suspended aerosol mass. The predictions of the two codes may look quite poor in the considered time window, but two remarks have to be made:

(i) For the second experimental point $(18,478 \mathrm{~s})$, a note is made in [9] highlighting that this value is not fully representative of the suspended aerosol mass since a loss of particles during the sampling process occurred.

(ii) The third and the fourth experimental points represent the suspended aerosol mass at $21,818 \mathrm{~s}$ and $22,568 \mathrm{~s}$ [9]. Between these two measurements a difference of about $30 \mathrm{~g}$ is shown, meaning that an abrupt deposition occurs in about $12.5 \mathrm{~min}$.

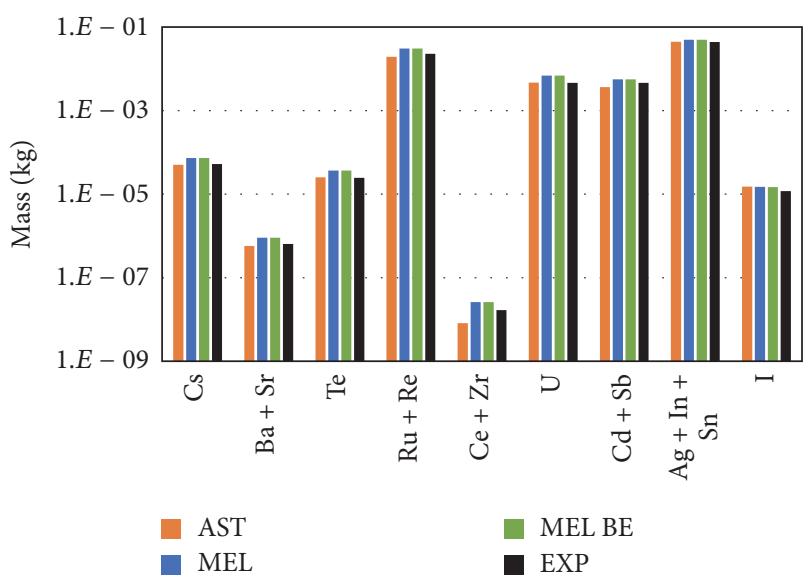

FIGURE 26: Masses deposited onto the bottom containment vessel surface before the washing phase.

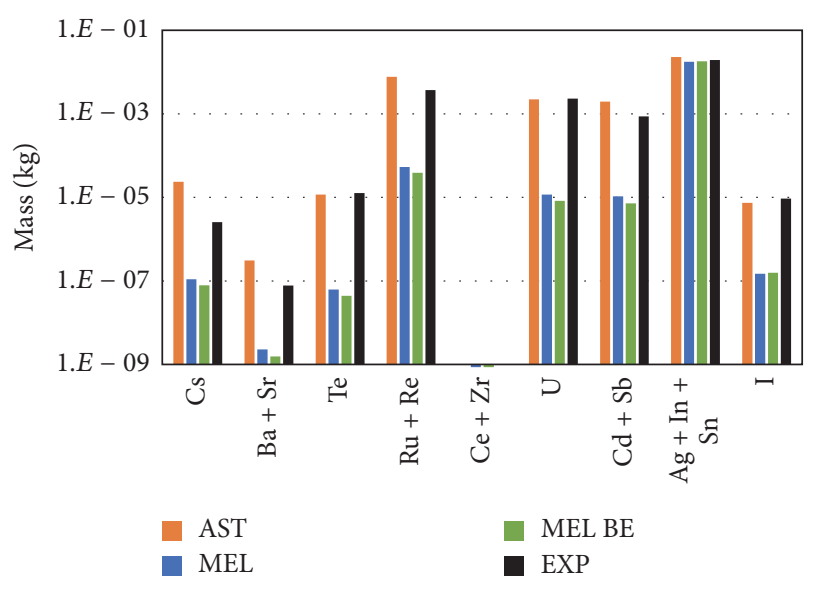

FIGURE 27: Masses deposited onto the wet condenser surfaces and the vertical walls after the washing phase.

Considering the initial experimental data points except the second one, both codes roughly match the experimental data. A much smoother deposition behavior is shown by both codes, with the experimental "peak" at 21,818 s being reached at about 17,000 s in the calculations. The suspended aerosol mass trends obtained with both codes are similar to those reported in [25], even if in [25] maximum suspended aerosol masses of $0.06 \mathrm{~kg}$ between $16,000 \mathrm{~s}$ and $19,000 \mathrm{~s}$ were reported.

After 23,000 s, the experimental data points are sufficient to stress that both codes well match the experimental evolution of the suspended aerosol mass.

In Figures 26 and 27, the masses of the different elements deposited onto the bottom containment vessel surface before the washing phase and the masses deposited on the wet condenser surfaces and the vertical walls after the washing phase are reported. The masses deposited on the bottom surface are well predicted by both codes. Only minor uncertainties are shown for $\mathrm{Ce}$ and $\mathrm{Zr}$, probably because of their very low amount in containment. On the contrary, significant discrepancies are shown by MELCOR for the 


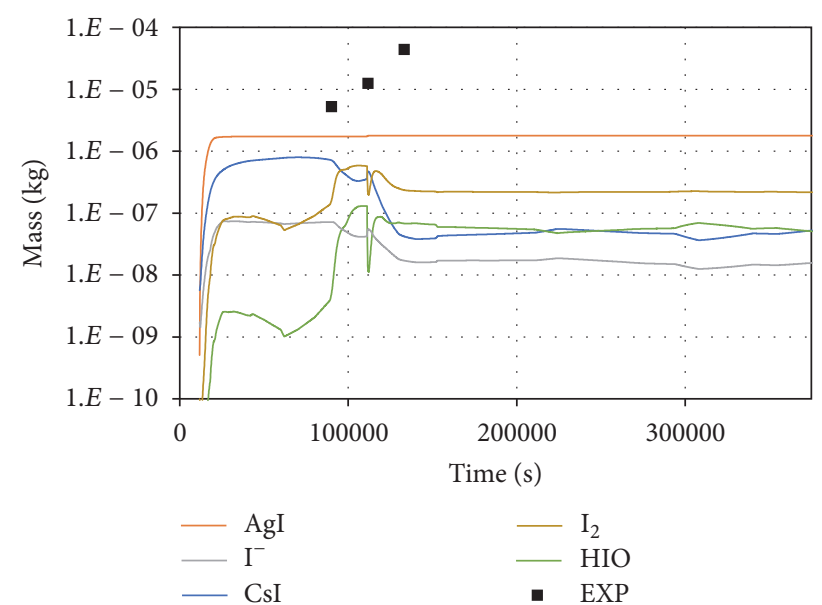

FIGURE 28: Iodine speciation in the sump water (MELCOR default case).

masses deposited on the wet condenser surfaces and on the vertical walls. For ASTEC, the only remark is related to the important overestimation of the Cs mass (one order of magnitude). MELCOR provides quite poor results for the deposited masses because aerosols on the condenser surfaces are captured only by the condensed water film (which flows into the sump water). This result is not due to a user's assumption, but it is the normal resulting behavior of the water-film tracking model, as explicitly declared by the sensitivity coefficient no. 7136 (solubility of RN classes in water films) [21]. Such value could be changed by the user, but no sensitivity analyses have been performed due to the absence of information about the repartition coefficient between the liquid film and the structure.

The evolution of the masses for the different iodine species inside the sump is reported in Figures 28 and 29 for MELCOR and ASTEC, respectively. No appreciable differences were shown between the two investigated MELCOR cases (default and best estimate cases), so only the results for the default case will be discussed in the following. The main aspects that should be stressed are as follows:

(i) A significant difference exists in the total iodine mass flowing inside the sump water. In ASTEC about $3.5 E-5 \mathrm{~kg}$ of iodine flows into the sump water, in MELCOR only $2.0 E-6 \mathrm{~kg}$. The MELCOR result is quite surprising because in the MELCOR model the aerosol mass deposited onto the wet condenser surfaces is completely routed toward the sump water; hence an overestimation of the iodine in the sump was expected. Since the iodine mass deposited on the bottom vessel surface is well captured, the only explanation for this lack of iodine mass in the sump is an overprediction of its presence in the atmosphere. The sump and the surrounding atmosphere exchange iodine basing on the conditions established at the interface of these two parts. This poor prediction was quite expected considering that the general modelization of the iodine chemistry in MELCOR does not reflect the actual state-of-the-art [26]. In turn, better

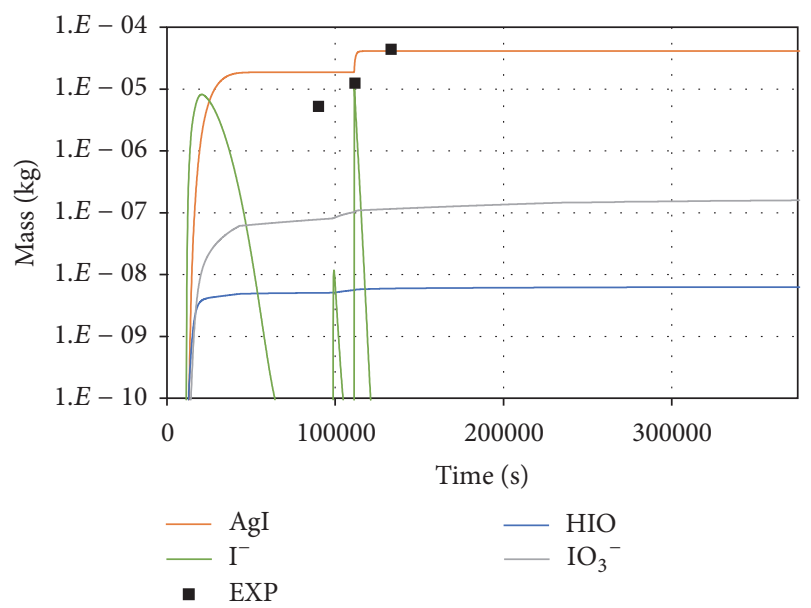

FIGURE 29: Iodine speciation in the sump water (ASTEC).

results are shown for ASTEC, and a good agreement with experimental data is shown.

(ii) Iodine is mainly found in the AgI form for both codes. This result was expected considering the relevant amount of Ag released inside the containment vessel $(0.05 \mathrm{~kg})$ [26].

(iii) An important quantity of CsI is formed by MELCOR. On the contrary, CsI is not present in ASTEC because the code automatically selects the chemical reactions that can occur during the calculation performed. For a stand-alone containment analysis, the reactions involving $\mathrm{Cs}$ and Iodine are not considered because the containment thermal-hydraulics conditions prevent the formation of CsI. This assumption is automatically made by the code, and it is based on the actual state-of-the-art on iodine chemistry [26]. For this reason, the formation of CsI in MELCOR is unrealistic, and it is due to the actual poor iodine modelling implemented in MELCOR, which mainly reflects the conclusions reported in [27].

(iv) $\mathrm{I}_{2}, \mathrm{I}^{-}$, $\mathrm{HIO}$, and $\mathrm{IO}_{3}{ }^{-}$behaviors are completely different for the two codes. In MELCOR, an important fraction of iodine is also found under $\mathrm{I}^{-}, \mathrm{HIO}$, and $\mathrm{I}_{2}$ forms. In ASTEC no $\mathrm{I}_{2}$ is found inside the sump, while small amounts of $\mathrm{HIO}$ and $\mathrm{IO}_{3}{ }^{-}$are shown. In turn, $\mathrm{I}^{-}$is rapidly dissolved and converted to other chemical forms (mainly AgI) once entered in the sump. $\mathrm{I}^{-}$then reappears during the washing phase and the precedent preparatory actions, but it is rapidly dissolved again once ending the washing phase. In any case, the iodine behavior shown by ASTEC agrees quite well with the actual state-of-the-art [26].

In general, the aerosol and FP predictions are not completely satisfactory because of the too low iodine mass flowing inside the sump. Regarding the speciation in the sump, MELCOR shows an important amount of AgI and CsI during the degradation and the aerosol phases; then CsI is partially dissociated into $\mathrm{I}_{2}$ during the washing and the chemistry 


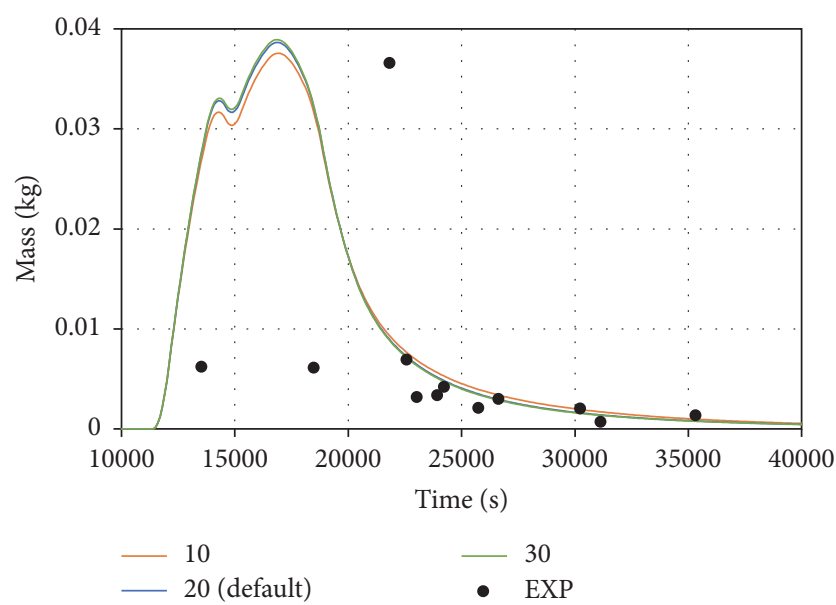

FIGURE 30: Results of the MELCOR sensitivity analyses on NPSC-suspended aerosol mass.

phases. In ASTEC, iodine is found mainly under the AgI form for the entire test, and for short periods also under the $\mathrm{I}^{-}$form. Of these two behaviors, the ASTEC one is the most reliable one since it reflects the actual state-of-the-art on iodine chemistry in a sump [26].

\section{Aerosols and Fission Products Sensitivity Analyses}

The influence of different input parameters has been investigated through a quite large execution of sensitivity analyses. In the following, the findings of these analyses will be briefly discussed. Regarding the two MELCOR M3 cases investigated (default and best-estimate) minor differences were shown, so in the following only the results of the M3 default case will be reported.

The main input parameters investigated for both codes were as follows:

(i) Number of Particle Size Classes (NPSC). This parameter has no physical meaning, but it is the number of intervals (classes) in which the log-normal distribution of the injected aerosols is subdivided. A default value of 10 is suggested for MELCOR, while for ASTEC no default values are provided [21]. In the present paper five sensitivity cases have been investigated, setting this parameter to 10, 20 (default case), 30, 40, and 50. The cases with NPSC sets to 20,30, 40, and 50 have provided identical results, while NPSC sets to 10 minor differences were shown for the suspended aerosol mass. In Figures 30 and 31, the influence of this parameter on the suspended aerosol mass in MELCOR and ASTEC calculations is reported. Hence, the results highlight that this parameter has only a minor influence on the overall aerosols and FPs behavior. With a NPSC set to 10 slightly lower computation times are required to perform the calculation, but the difference is not so marked.

(ii) Dynamic Shape Factor for Agglomeration Processes. A default value of 1.0 is suggested for both codes [18, 21].

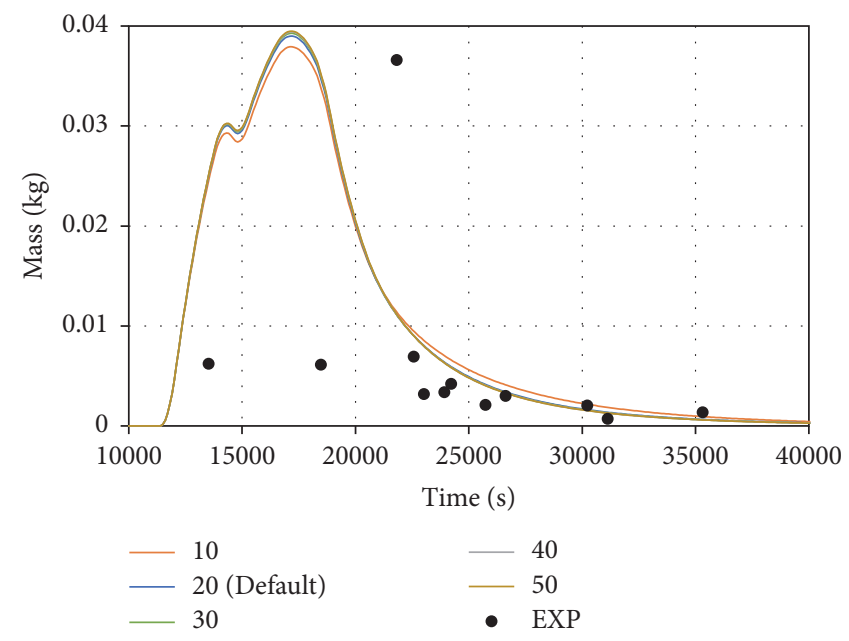

FIGURE 31: Results of the ASTEC sensitivity analyses on NPSC-suspended aerosol mass.

Four sensitivity analyses have been performed, setting this parameter to 1.0 (default case), 1.5, 2.0, and 3.0. A value of 1.0 means that the aerosol particles are spherical, 1.5 means that are similar to sand, and 2.0 means that they are similar to talc [28]. This parameter has a great influence on the suspended aerosol mass evolution in both codes, but only minor effects are shown among the deposition repartition among the different surfaces. Increasing the dynamic shape factor slows the deposition processes (because the agglomeration is less strong), leading to results not comparable with the experimental ones. Regarding the deposition repartition among the different surfaces scattered effects are shown. In ASTEC, the increase of the dynamic shape factor increases the deposition onto the vertical walls and on the wet condenser surfaces, while in MELCOR different behaviors are shown for each element. For $\mathrm{Cs}, \mathrm{Te}, \mathrm{Ru}$, and Re the deposition on the vertical walls and on the wet condenser surfaces is stronger, for $\mathrm{Ba}$, $\mathrm{Sr}, \mathrm{Cd}$, and $\mathrm{Sb}$ it is weaker, and for $\mathrm{U}, \mathrm{Ag}, \mathrm{Sn}, \mathrm{In}$, and $\mathrm{I}_{2}$ no appreciable differences were shown. In Figures 32, 33, 34, and 35 , the influence on the suspended aerosol mass evolution and on the mass deposited onto the vertical walls and the wet condenser surfaces is shown.

(iii) Aerosol Density. No experimental data nor default values were provided for the aerosol density, but in other works values spanning from $1,000 \mathrm{~kg} / \mathrm{m}^{3}$ to $10,000 \mathrm{~kg} / \mathrm{m}^{3}$ were suggested $[29,30]$. In the present paper, five sensitivity cases were investigated, setting the density value to $1,000 \mathrm{~kg} / \mathrm{m}^{3}$ (default MELCOR value for wet aerosols [21]), 3,000 kg/m $\mathrm{m}^{3}$ (default case), $10,000 \mathrm{~kg} / \mathrm{m}^{3}, 15,000 \mathrm{~kg} / \mathrm{m}^{3}$, and $20,000 \mathrm{~kg} / \mathrm{m}^{3}$. The default aerosol density assumed $\left(3000 \mathrm{~kg} / \mathrm{m}^{3}\right)$ was inferred from previous works $[29,30]$. The increase of the aerosol density leads to a faster deposition onto the vertical walls in MELCOR, and on the bottom surface in ASTEC. The increase of the aerosol density obviously decreases also the maximum aerosol mass suspended inside the containment due to the faster deposition process. In Figures 36, 37, 38, and 39, the effects of density variation on the suspended aerosol mass 


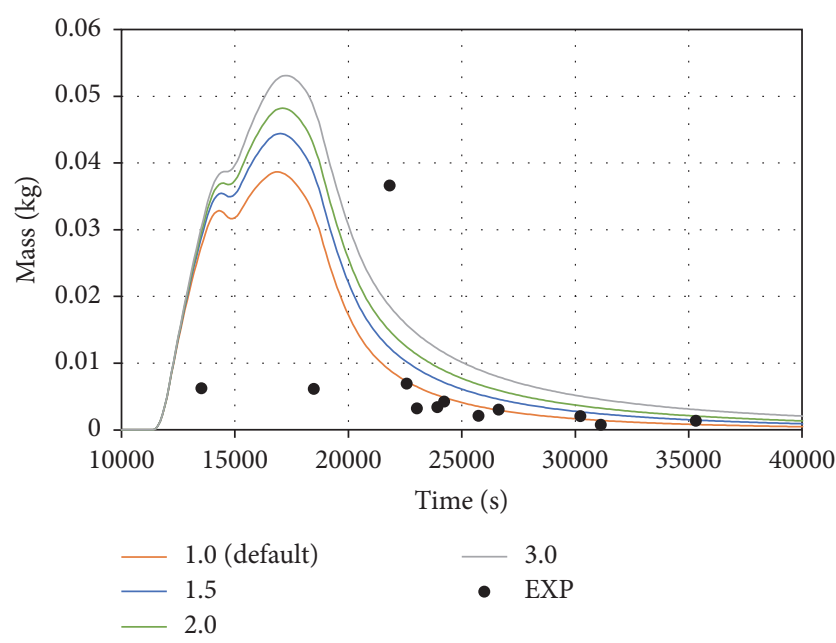

FIgURE 32: Results of the MELCOR sensitivity analyses on the dynamic shape factor-suspended aerosol mass.

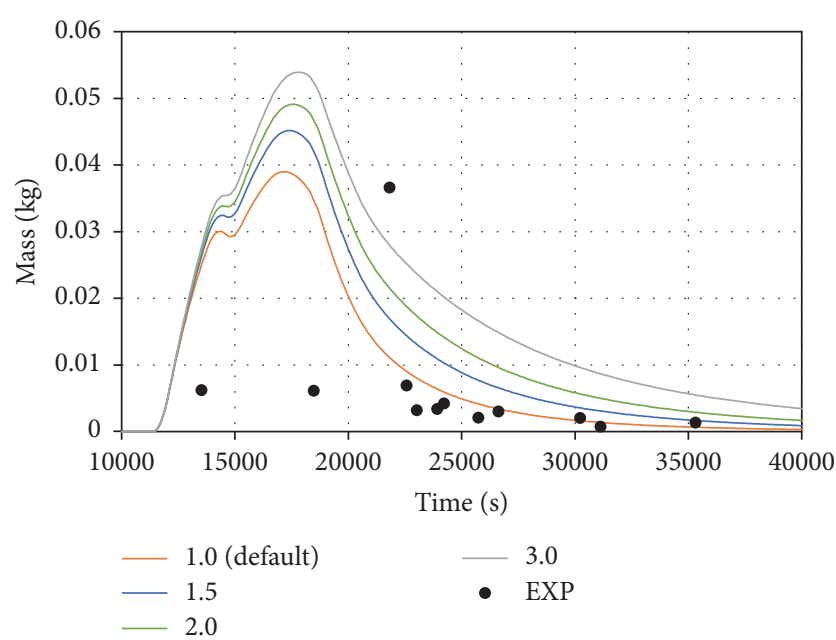

FIGURE 33: Results of the ASTEC sensitivity analyses on the dynamic shape factor-suspended aerosol mass.

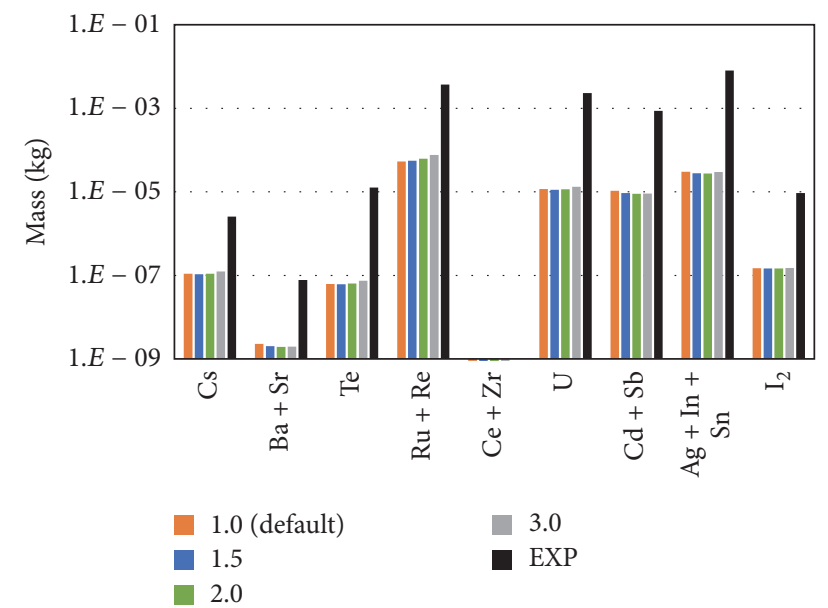

Figure 34: Results of the MELCOR sensitivity analyses on the dynamic shape factor-deposited aerosol mass on the vertical walls and on the wet condenser surfaces.

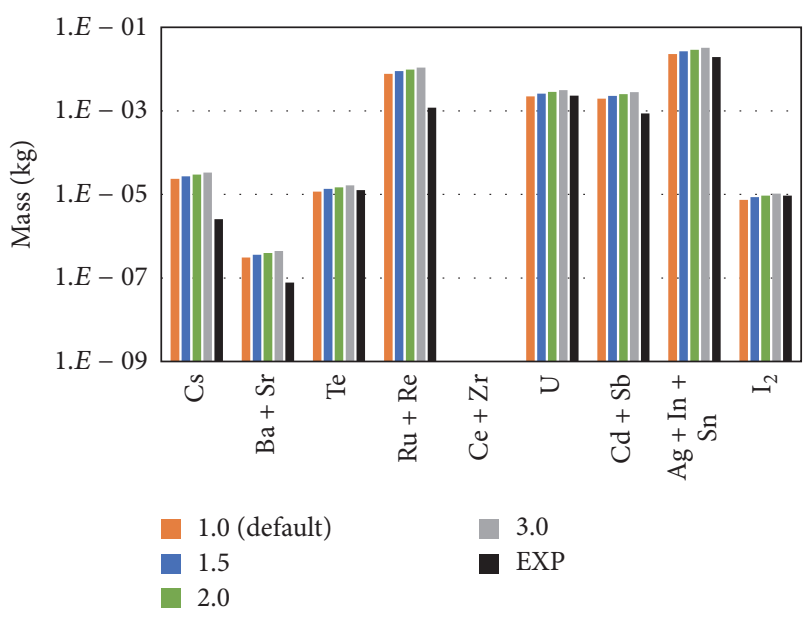

FIGURE 35: Results of the ASTEC sensitivity analyses on the dynamic shape factor-deposited aerosol mass on the vertical walls and on the wet condenser surfaces.

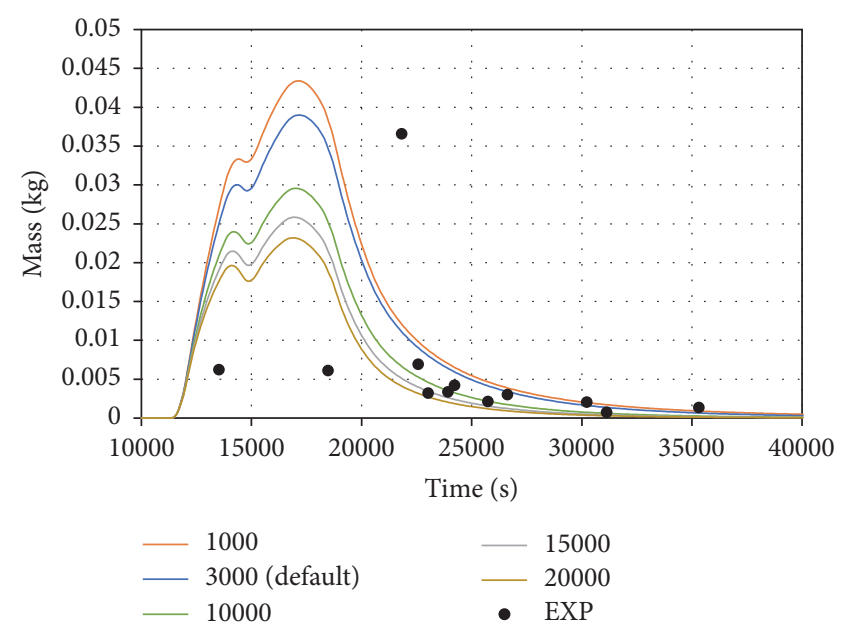

FIGURE 36: Results of the ASTEC sensitivity analyses on the aerosol density-suspended aerosol mass.

and on the deposition onto the vertical walls and on the wet condenser surfaces are shown.

(iv) Agglomeration Shape Factor. A default value of 1.0 is suggested for both codes [18, 21]. Four sensitivity analyses have been executed, setting this parameter equal to $0.5,1.0$ (default case), 2.0, and 3.0. The effects on the ASTEC and MELCOR calculations are somewhat similar to those shown with an increased aerosol density. In ASTEC, the increase of the agglomeration shape factor leads to a greater deposition on the bottom surface, while in MELCOR no remarkable effects on the deposition process onto the containment surfaces are shown because a greater fraction of the aerosol mass is transported into the sump. In Figures 40 and 41, the effects of this parameter on the suspended aerosol mass are shown.

(v) Turbulence Dissipation Rates. In ASTEC, a default value of $0.02 \mathrm{~m}^{2} / \mathrm{s}^{3}$ is suggested [18], while in MELCOR the 


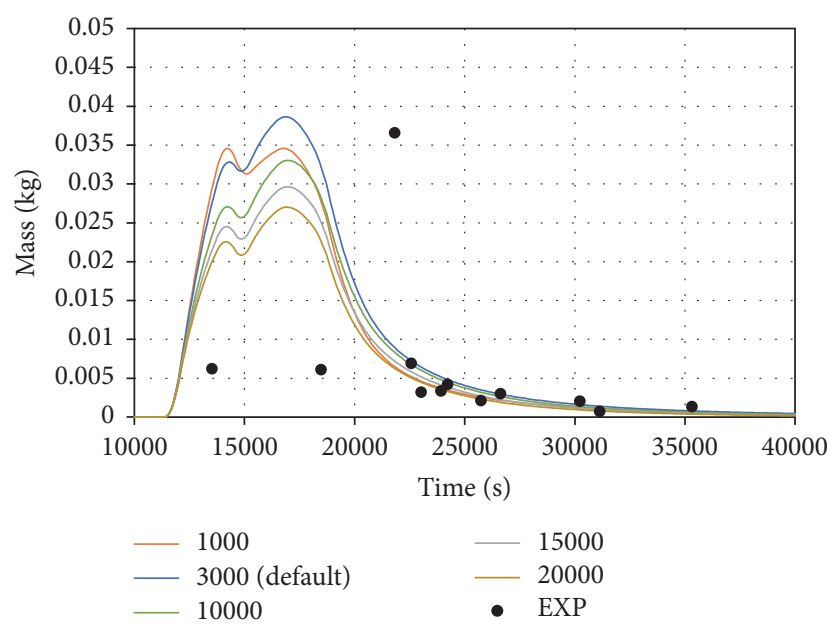

FIGURE 37: Results of the MELCOR sensitivity analyses on the aerosol density-suspended aerosol mass.

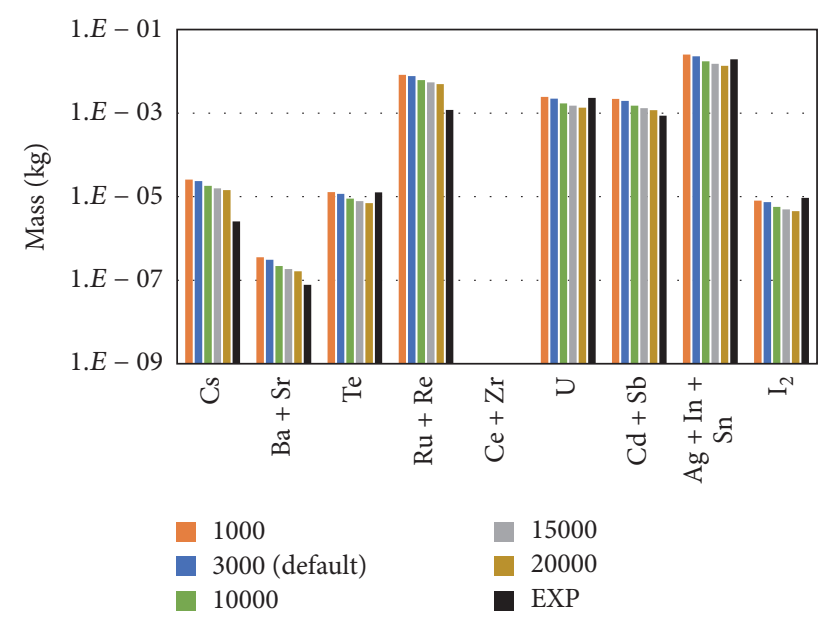

FIGURE 38: Results of the ASTEC sensitivity analyses on the aerosol density-deposited aerosol mass on the vessel vertical walls and on the wet condenser surfaces.

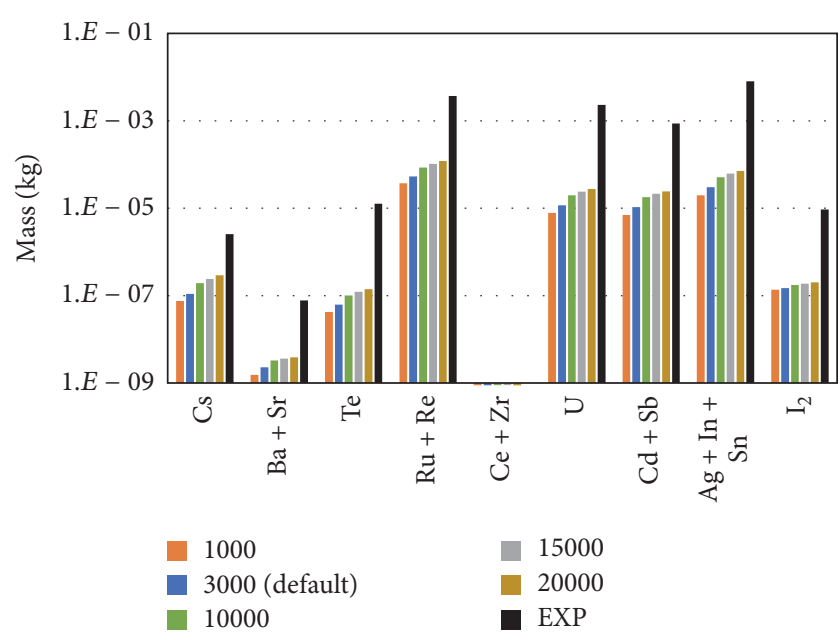

FIgURE 39: Results of the MELCOR sensitivity analyses on the aerosol density-deposited aerosol mass on the vessel vertical walls and on the wet condenser surfaces.

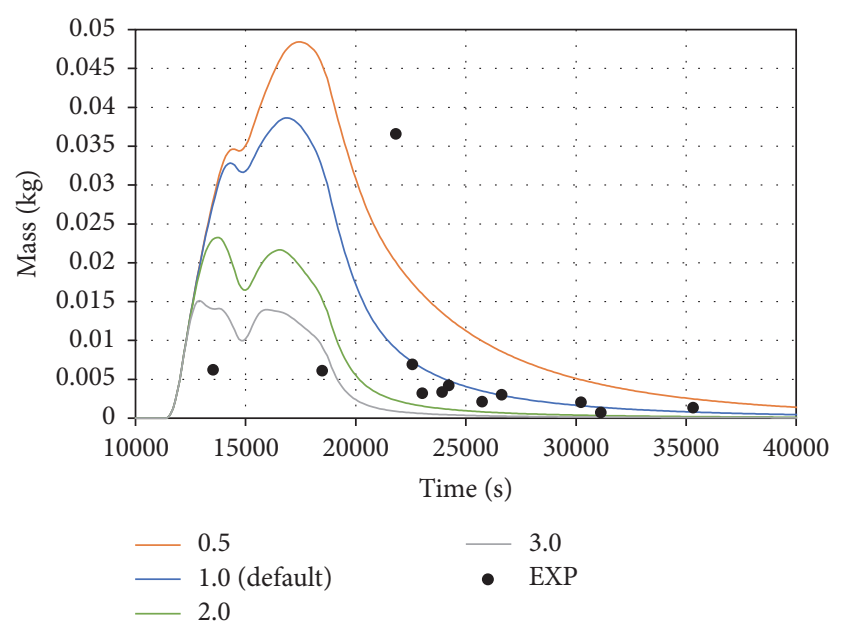

FIgURE 40: Results of the MELCOR sensitivity analyses on the agglomeration shape factor-suspended aerosol mass.

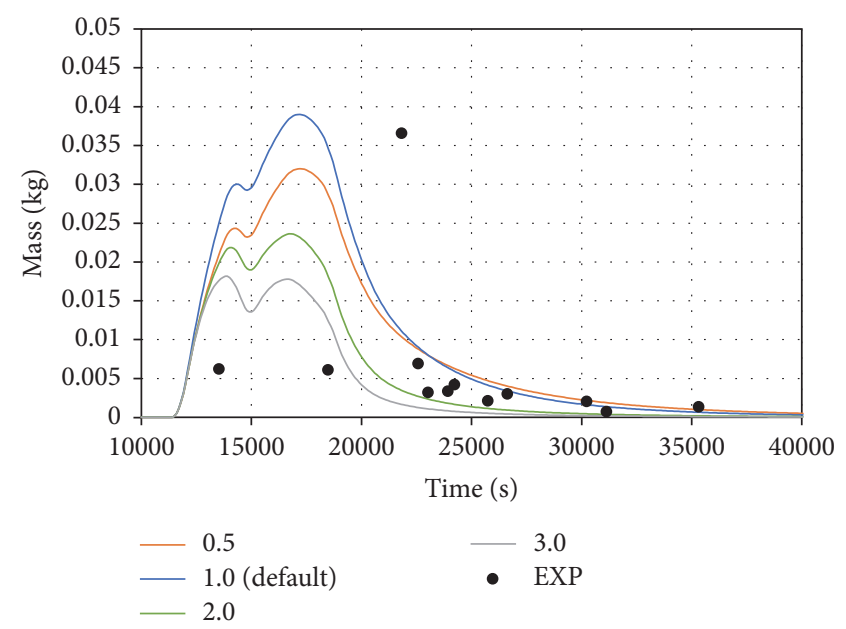

FIgURE 41: Results of the ASTEC sensitivity analyses on the agglomeration shape factor-suspended aerosol mass.

default value is set to $0.001 \mathrm{~m}^{2} / \mathrm{s}^{3}$ [21]. Five sensitivity analyses have been executed, setting this parameter to $0.001 \mathrm{~m}^{2} / \mathrm{s}^{3}, 0.005 \mathrm{~m}^{2} / \mathrm{s}^{3}, 0.01 \mathrm{~m}^{2} / \mathrm{s}^{3}, 0.02 \mathrm{~m}^{2} / \mathrm{s}^{3}$ (default case), and $0.03 \mathrm{~m}^{2} / \mathrm{s}^{3}$. In ASTEC, no appreciable differences were shown among the different cases, while in MELCOR differences exist on the suspended aerosol mass but not on the deposited mass amount on the different surfaces. In Figure 42, the effects of this parameter on the MELCOR suspended mass are shown.

(vi) Particle Sticking Probability. A default value of 1.0 is suggested for both codes [18, 21]. Four sensitivity cases have been investigated, setting this parameter to: 0.5, 1.0 (default case), 2.0, and 3.0. A strong influence on the suspended aerosol mass is shown in MELCOR, but no remarkable differences on the deposition magnitude on the different containment surfaces were shown. In ASTEC, the influence is lower than that in MELCOR, but again no differences were shown on the magnitude for the deposition on the different 


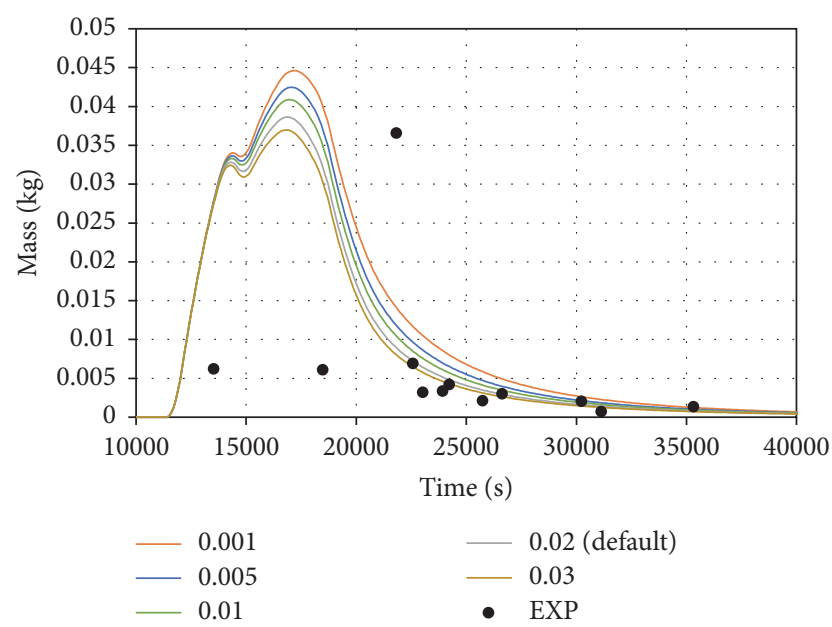

FIGURE 42: Results of the MELCOR sensitivity analyses on the turbulence dissipation rate-suspended aerosol mass.

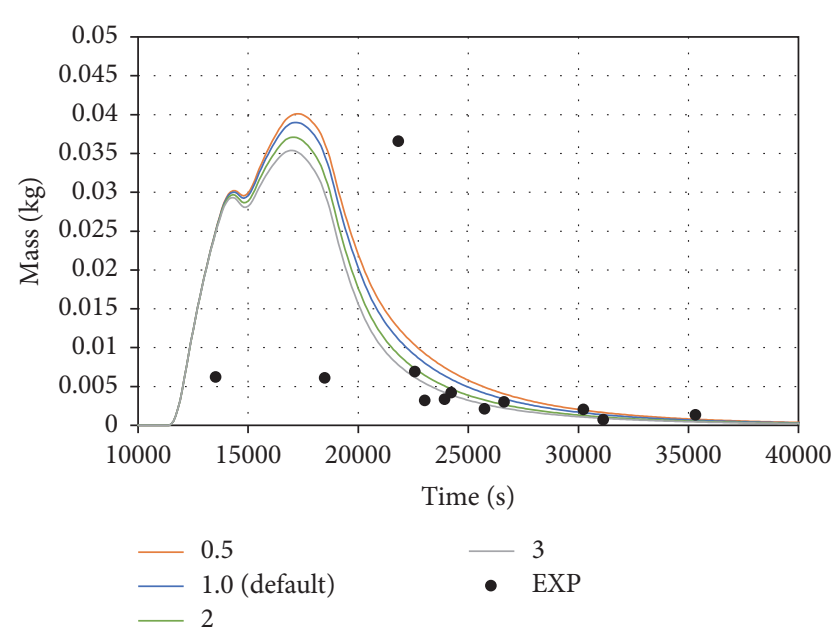

FIGURE 43: Results of the ASTEC sensitivity analyses on the particle sticking probability-suspended aerosol mass.

containment surfaces. In Figures 43 and 44, the effects of this parameter on the suspended aerosol mass are reported.

(vii) Ratio of the Thermal Conductivity of the Gas Phase to the Thermal Conductivity of the Aerosol Particles. Defaults values of $5.0 E-2$ and $5.0 E-3$ are suggested for MELCOR and ASTEC, respectively $[18,21]$. Four sensitivity cases have been performed, setting this parameter to $5.0 E-2$ (default case), $5.0 E-3,5.0 E-4$, and 5.0E-5. In both codes, the different cases investigated have provided the same results, so the influence of this parameter seems negligible.

(viii) Aerosol Mass Median Diameter (AMMD) and Its Geometric Standard Deviation (GSD). A maximum and a minimum AMMD and GSD values for the entire aerosol population were provided in the FPT-0 Final Report [9]. For this reason, three sensitivity analyses were carried out setting AMMD to $0.9 \mu \mathrm{m}, 1.3 \mu \mathrm{m}$ (default case), and $1.7 \mu \mathrm{m}$, and GSD to $2.0,2.15$ (default case), and 2.3. The modification of the

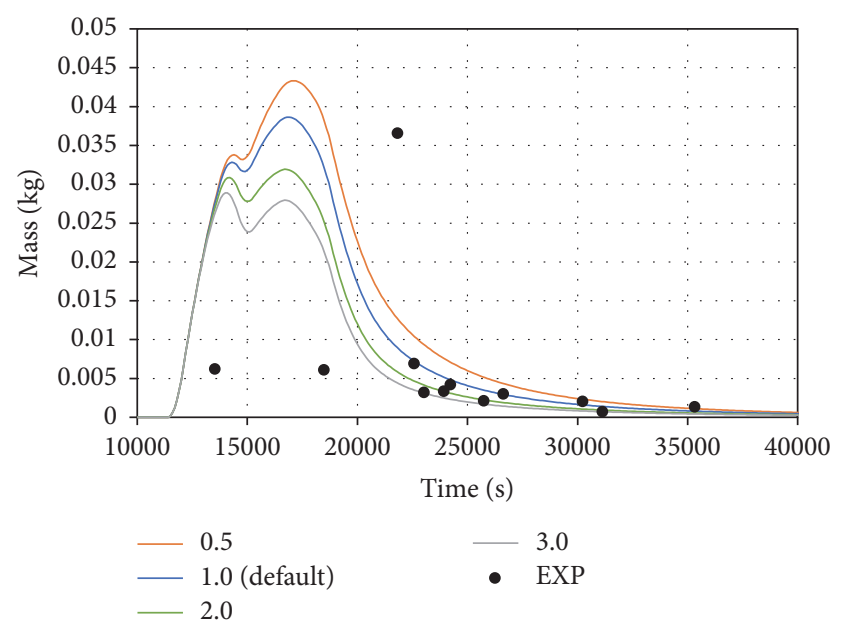

FIGURE 44: Results of the MELCOR sensitivity analyses on the particle sticking probability-suspended aerosol mass.

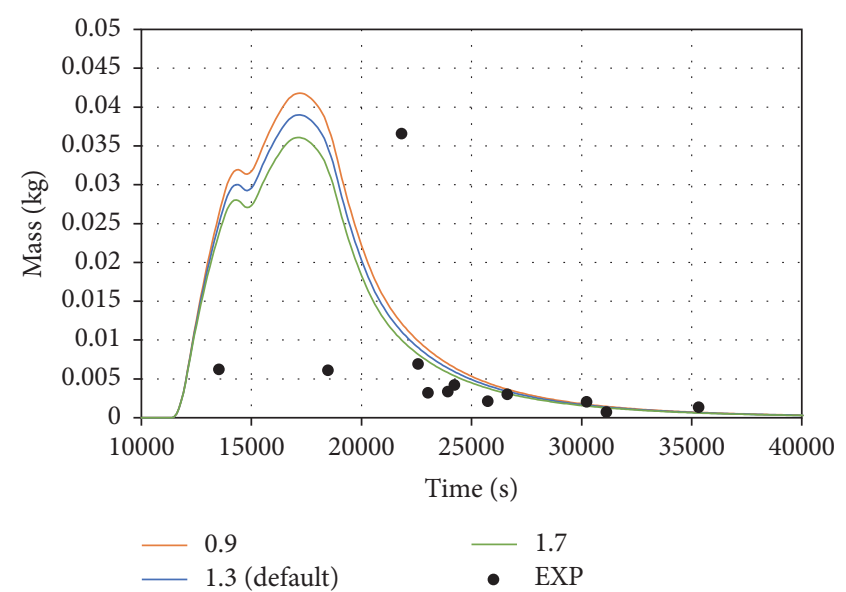

FIgURE 45: Results of the ASTEC sensitivity analyses on AMMD-suspended aerosol mass.

GSD value provided negligible results. On the contrary, a greater influence for AMMD was highlighted. Such effects are mainly focused on the suspended aerosol mass evolution, but not for the magnitude of the deposition process on the different containment surfaces. In Figures 45 and 46, the effects of AMMD on the suspended aerosol mass are reported.

Both codes implement other specific input parameters. Some of these parameters were investigated, but a code-tocode comparison was not executed. These specific parameters for ASTEC were as follows:

(i) Influence of the Aerosol Particles on the Gas Density. The influence of the aerosol particles on the gas density has a negligible effect on the ASTEC results.

(ii) Flag to Dynamically Calculate the Condensation Time Step. Five cases were investigated, changing the surface tension of a droplet in the atmosphere: in the default case 


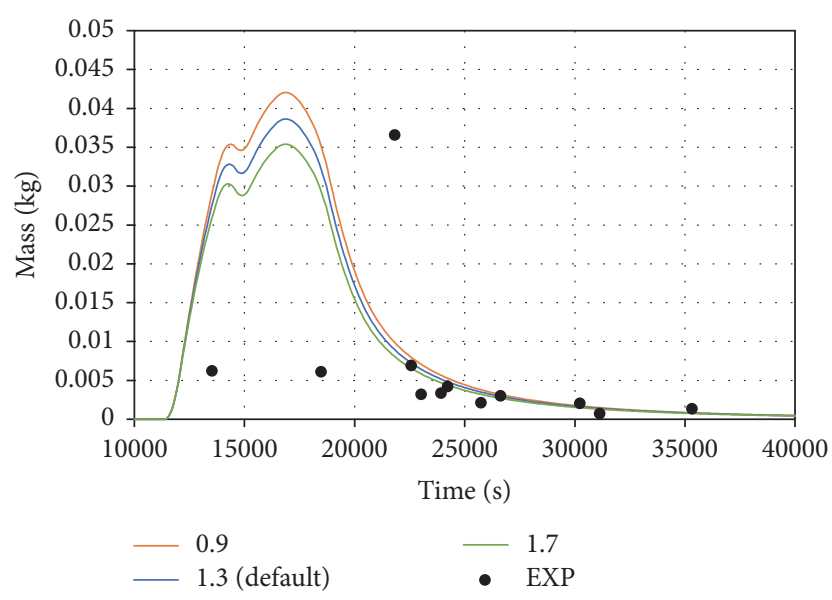

FIGURE 46: Results of the MELCOR sensitivity analyses on AMMD-suspended aerosol mass.

the condensation time step was not dynamically calculated, while in the other cases such time step was dynamically calculated considering four different droplet surface tension values $(0.0586 \mathrm{~N} / \mathrm{m}, 0.0598 \mathrm{~N} / \mathrm{m}, 0.0572 \mathrm{~N} / \mathrm{m}$, and $0.0559 \mathrm{~N} / \mathrm{m}$ ). These four values were calculated considering different droplet equilibrium temperature values: $100^{\circ} \mathrm{C}$ $(0.0586 \mathrm{~N} / \mathrm{m}), 95^{\circ} \mathrm{C}(0.0598 \mathrm{~N} / \mathrm{m}), 105^{\circ} \mathrm{C}(0.0572 \mathrm{~N} / \mathrm{m})$, and $110^{\circ} \mathrm{C}(0.0559 \mathrm{~N} / \mathrm{m})$. No differences were shown among the results of the investigated cases.

(iii) Air Molecular Weight. A default value of $23.5 \mathrm{~kg} / \mathrm{kmol}$ is suggested based on the common air composition, but in the present scenario the containment vessel atmosphere is mainly filled with $\mathrm{N}_{2}$, so a value closer to the $\mathrm{N}_{2}$ molecular weight $(28.96 \mathrm{~kg} / \mathrm{kmol})$ may be more appropriate. Four sensitivity cases have been performed setting this parameter to $23.5 \mathrm{~kg} / \mathrm{kmol}$ (default case), $28.96 \mathrm{~kg} / \mathrm{kmol}$ (atmosphere only filled with $\mathrm{N}_{2}$ ), $18.02 \mathrm{~kg} / \mathrm{kmol}$ (atmosphere only filled with $\mathrm{O}_{2}$ ), and $20,76 \mathrm{~kg} / \mathrm{kmol}$ (atmosphere filled with $50 \% \mathrm{~N}_{2}$ and $50 \% \mathrm{O}_{2}$ ). Negligible differences were shown among the results of the investigated cases.

(iv) Relation Employed to Calculate the Collision Efficiency for Gravitational and Turbulent Coagulation. The recommended model is the Pruppacher and Klett one, but the Fuchs model and the truncated Pruppacher and Klett model are implemented in the ASTEC code as well. For this reason, three sensitivity cases have been performed, one for each implemented model. A minor difference on the suspended aerosol mass among the Pruppacher and Klett models (both) and the Fuchs model was highlighted, although the three models predict values higher than the experimental ones at least until 25,000 s. In Figure 47, the entity of this difference for the suspended aerosol mass is shown.

(v) Thickness of the Water Film Used for Drainage and Aerosol Washdown. No default values are suggested, so three sensitivity cases have been performed setting this parameter to $1.0 E-3 \mathrm{~m}, 1.0 E-4 \mathrm{~m}$ (default case), and $1.0 E-5 \mathrm{~m}$. No

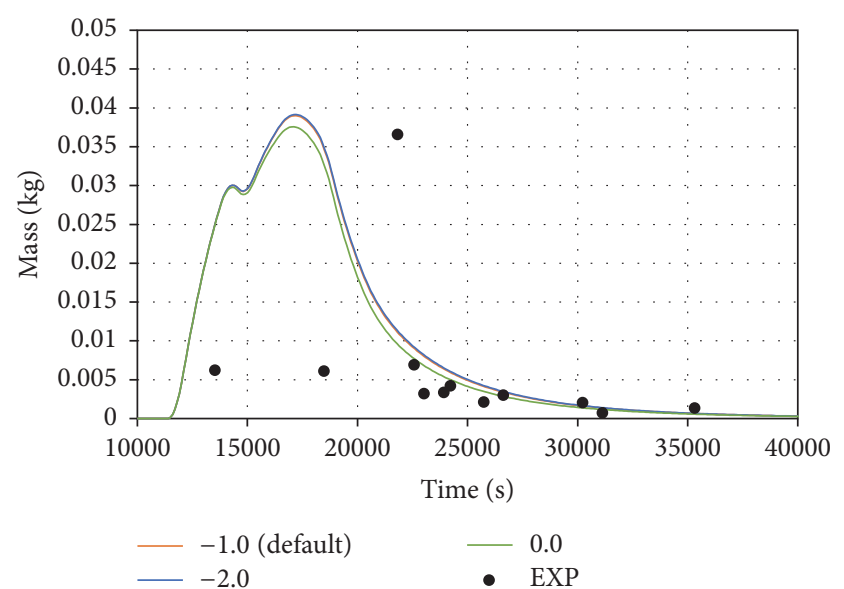

FIGURE 47: Results of the ASTEC sensitivity analyses on the relation employed to calculate the collision efficiency for gravitational and turbulent coagulation-suspended aerosol mass.

appreciable differences have been highlighted among these three cases.

(vi) Aerosol Deposition Velocity for Each Aerosol Component. No default values are suggested, so four sensitivity cases have been executed setting this parameter to $0.0 \mathrm{~m} / \mathrm{s}$ (default case), $1.0 E-2 \mathrm{~m} / \mathrm{s}, 1.0 E-3 \mathrm{~m} / \mathrm{s}$, and $1.0 E-4 \mathrm{~m} / \mathrm{s}$. No appreciable differences were found among these cases.

For MELCOR, these specific input parameters were investigated:

(i) Condensation of Water on All the Aerosol Particles or Only on Aerosol Particles Containing Water. Two sensitivity cases have been analyzed: one setting the condensation on all the aerosol particles (default case) and the other one setting the condensation only on the aerosol particles containing water. No differences were shown among the two cases.

(ii) Particle Slip Coefficient Influencing the Gravitational Deposition [21]. A default case of 1.257 is suggested in the MELCOR User's Guide [21], but three other values have been investigated setting this parameter to 1.0, 1.5, and 2.0. Minor differences were shown for the deposition magnitude on the vertical walls and on the wet condenser surfaces.

(iii) Constant Associated with the Thermal Accommodation Coefficient for the Thermophoresis Deposition Mechanism [21]. A default value of 2.25 (dimensionless) is suggested in the MELCOR User's Guide [21], but four other cases have been performed, setting this parameter to 1.0, 2.0, 2.5, and 3.0. As for the previous parameter, only minor differences were shown for the deposition magnitude on the vertical walls and on the wet condenser surfaces.

(iv) Diffusion Boundary Layer Thickness. A default value of $1.0 E-5 \mathrm{~m}$ is suggested in the MELCOR User's Guide [21], but four other cases have been executed, setting this value to $1.0 E-4 \mathrm{~m}, 5.0 E-4 \mathrm{~m}, 5.0 E-5 \mathrm{~m}$, and $1.0 E-6 \mathrm{~m}$. In 


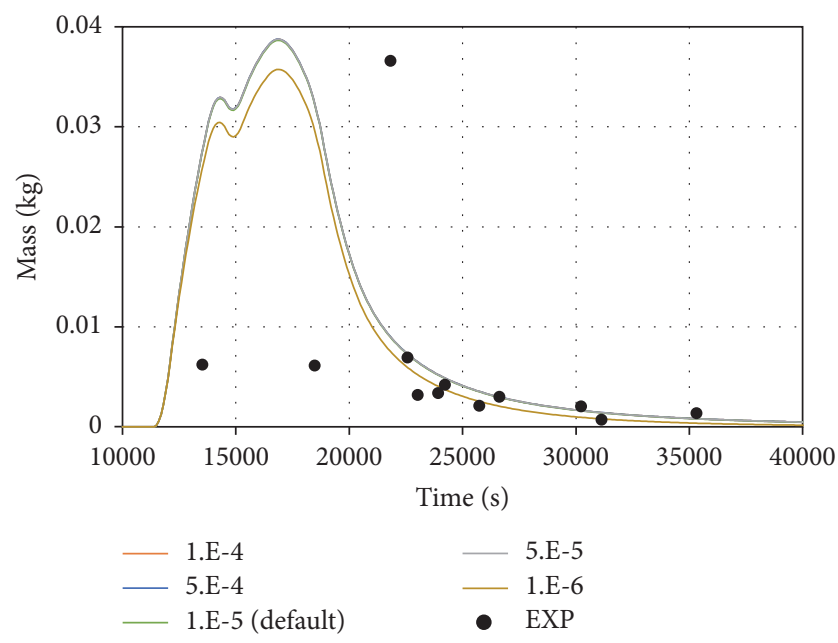

FIGURE 48: Results of the MELCOR sensitivity analyses on diffusion boundary layer thickness-suspended aerosol mass.

a previous work [31], a value of $1.0 E-4 \mathrm{~m}$ was suggested. With a diffusion boundary layer thickness set to $1.0 E-6$ the deposition process velocities are slightly overestimated, and a too fast deposition is shown, although the other values for the diffusion boundary layer thickness provided identical results, so it seems that this parameter has a poor influence on the aerosol behavior. In Figure 48, the effects on the suspended aerosol mass are reported.

(v) Partition of $\Gamma$ and HIO between Atmosphere and Sump. In the default case, the partitioning for both components is deactivated (as suggested in the User's Guidelines [21]), but two sensitivity cases have been performed, selectively activating the $\mathrm{I}^{-}$and the $\mathrm{HOI}$ partitioning. The activation of $\mathrm{I}^{-}$partitioning led to a quite important $\mathrm{I}^{-}$release from the sump water towards the atmosphere, influencing the iodine speciation. As shown in Figure 49, the same iodine species of the default case are formed, but the masses produced are more than one order of magnitude lower than the default case ones (except AgI). Also, the HIO partitioning has a great effect on the sump speciation during and after the washing phase (Figure 50). After the washing phase, the HIO partitioning and the $\mathrm{I}^{-}$partitioning show quite similar result.

\section{Conclusions}

In the present paper, a comparison between the ASTEC and MELCOR codes against the results of the Phébus FPT0 test has been executed. Three spatial nodalizations have been employed to stress that too simple nodalizations are not able to correctly simulate a complex thermal-hydraulic transient. These nodalizations have been also developed in the most identical way possible for both codes, but the different modelling approaches of certain aspects were all exploited, to obtain the best possible results with each code.

The most complex spatial nodalization (M3) had shown good thermal-hydraulic results, but some discrepancies were

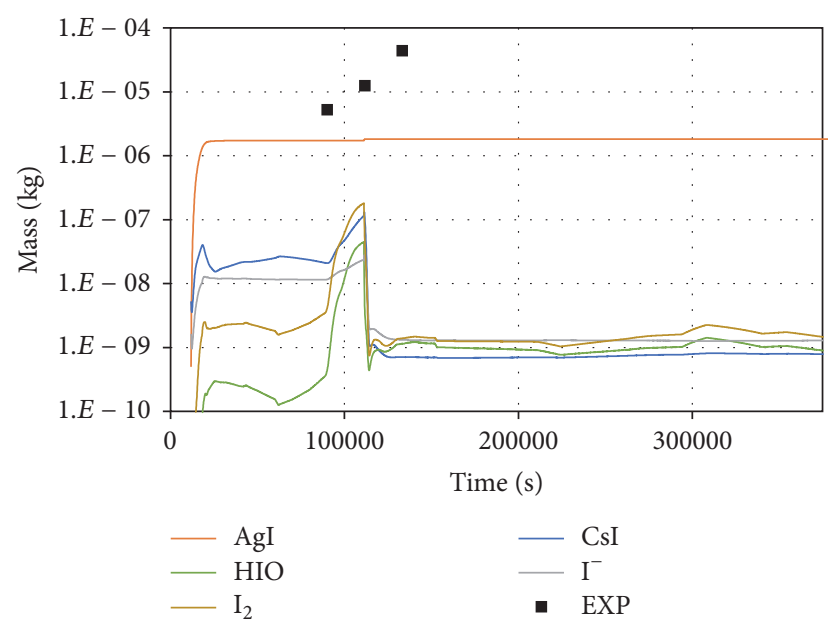

Figure 49: Effect of $\mathrm{I}^{-}$partitioning on the iodine atmospheric mass.

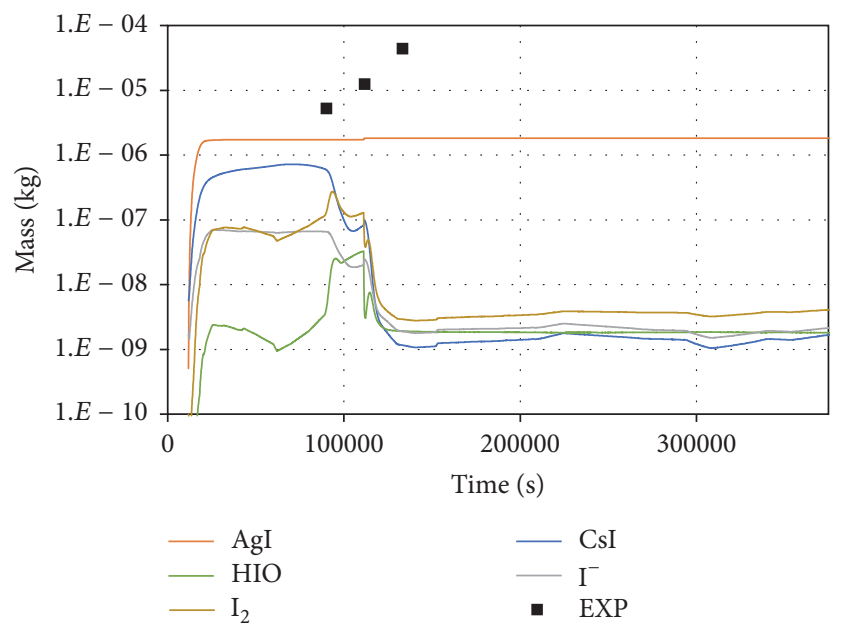

FIGURE 50: Effect of HOI partitioning on the iodine atmospheric mass.

shown for both codes. These discrepancies are mainly introduced by the performed user's assumptions. A clear example of these effects is shown during the time period of the preparatory actions before the washing phase, and during the beginning of the chemistry phase. Such effects are mainly focused on the atmospheric temperature predictions, which in turn influence the total containment pressure and the r.h. results although the aerosols' behavior is mainly influenced by the thermal-hydraulics conditions during the early $50,000 \mathrm{~s}$ of the test, but also the thermal-hydraulic transient during the other test phases becomes important for a correct evaluation of the iodine behavior in the sump water and in the atmosphere. Few experimental data were provided inside the FPT-0 Final Report [9], but some conclusions can be drawn:

(i) Probably, during the early FP injection phase, the calculated suspended aerosol mass is overestimated. However, only two experimental data points were provided during this period, so this conclusion cannot be completely ensured. 
TABLE 4: Summary of the sensitivity cases performed and importance for the ASTEC and MELCOR results.

\begin{tabular}{|c|c|c|}
\hline Parameter & Importance for ASTEC calculations & Importance for MELCOR calculations \\
\hline $\mathrm{I}^{-}$partitioning among sump water and atmosphere & 1 & High \\
\hline HIO partitioning among sump water and atmosphere & 1 & High \\
\hline Aerosol deposition velocity for each aerosol component & Low & 1 \\
\hline Dynamic shape factor for agglomeration processes & High & High \\
\hline $\begin{array}{l}\text { Collision efficiency for gravitational and turbulent } \\
\text { coagulation }\end{array}$ & High & 1 \\
\hline Aerosol density & High & High \\
\hline $\begin{array}{l}\text { Dynamic calculation of the time-step + Surface tension } \\
\text { of a droplet in the atmosphere }\end{array}$ & Low & 1 \\
\hline Agglomeration shape factor & High & High \\
\hline $\begin{array}{l}\text { Consideration of the aerosol particles presence for } \\
\text { calculating the gas density }\end{array}$ & Low & 1 \\
\hline Number of particle size classes & High & High \\
\hline Aerosol mass median diameter & High & High \\
\hline Geometric standard deviation & Low & Low \\
\hline Particle sticking probability & High & High \\
\hline $\begin{array}{l}\text { Thickness of water film used for drainage and aerosol } \\
\text { washdown }\end{array}$ & Low & 1 \\
\hline $\begin{array}{l}\text { Thermal conductivity of gas divided by thermal } \\
\text { conductivity of aerosol particle }\end{array}$ & Low & Low \\
\hline Turbulence dissipation rate & Minor & High \\
\hline Molecular weight of gas & Minor & 1 \\
\hline Diffusion boundary layer thickness & 1 & Minor \\
\hline Thermal accommodation coefficient & 1 & Minor \\
\hline Particle slip coefficient & 1 & Minor \\
\hline Condensation onto wet aerosols & 1 & Low \\
\hline
\end{tabular}

(ii) The MELCOR default and best estimate cases predict slightly different aerosol behavior, but such differences are of minor importance.

(iii) The magnitude of the deposition processes is well captured by ASTEC, while for MELCOR somewhat poor results are shown, especially for the deposition onto the vertical walls and on the wet condenser surfaces, although these results are mainly due to the particular models implemented in the MELCOR code (the FPs deposited onto a structure are completely washed away if a condensate film exists on its surface).

(iv) The performed sensitivity analyses have shown that several parameters influence the aerosol behavior. The most influencing parameters were found to be the aerosol density, the dynamic agglomeration factor, the agglomeration factor, and the AMMD. Other parameters slightly influencing the code predictions are the sticking probability, the number of particle size classes, the turbulence dissipation rate, the relation employed to calculate the collision efficiency for gravitational and turbulent coagulation (only in ASTEC), the air molecular weight (only in ASTEC), the diffusion boundary layer thickness (only in MELCOR), the particle slip coefficient influencing the gravitational deposition (only in MELCOR), and the constant associated with the thermal accommodation coefficient for the thermophoresis deposition mechanism (only in MELCOR). Other investigated parameters with a negligible influence were the injection GSD, the thermal conductivity of gas divided by thermal conductivity of aerosol particle, the aerosol deposition velocity (only in ASTEC), the dynamic calculation of the condensation time step (only in ASTEC), the thickness of water film used for drainage and aerosol washdown (only in ASTEC), the consideration of the aerosol particles presence for calculating the gas density (only in ASTEC), and the aerosol condensation on all aerosols or only on wet aerosols (only in MELCOR). In Table 4, a summary of the sensitivity cases performed is reported.

Quite important differences were shown about the prediction of the iodine behavior in the sump. Both codes-but especially MELCOR-fail to catch the correct repartition among the deposited iodine on structures, the iodine inside the sump water, and the suspended iodine mass. This poor estimation may be also one of the main causes behind the different iodine speciation in the sump water. In the ASTEC simulations, iodine is found mainly under AgI and $\mathrm{I}^{-}$forms, in MELCOR analysis, in AgI, CsI, and $\mathrm{I}_{2}$. Other species are also formed, 
as $\mathrm{HIO}$ (both codes) and $\mathrm{IO}_{3}{ }^{-}$but their amounts are almost negligible. The ASTEC predictions seem the most realistic ones, thanks to the important formation of AgI and the absolute absence of CsI. A sensitivity analysis has been also carried out in MELCOR for the evaluation of the influence of the activation/deactivation of the $\mathrm{I}^{-}$and HOI partitioning on the iodine behavior in the sump. These cases have highlighted that the partition of both compounds leads to quite different results, so their activation should be carefully evaluated on case by case basis.

\section{Nomenclature}

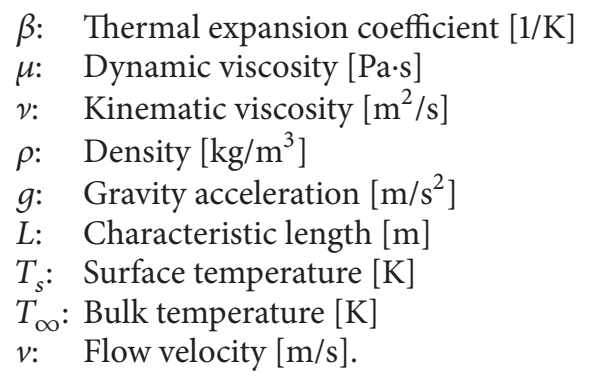

\section{Conflicts of Interest}

The authors declare that they have no conflicts of interest.

\section{References}

[1] J.-P. Van Dorsselaere, A. Auvinen, D. Beraha et al., "Recent severe accident research synthesis of the major outcomes from the SARNET network," Nuclear Engineering and Design, vol. 291, pp. 19-34, 2015.

[2] A. Bentaïb, H. Bonneville, G. Cénérino et al., Nuclear Power Reactor Core Melt Accidents, ESP Sciences, 2015.

[3] B. Clément and R. Zeyen, "The objectives of the Phébus FP experimental programme and main findings," Annals of Nuclear Energy, vol. 61, pp. 4-10, 2013.

[4] O. De Luze, T. Haste, M. Barrachin, and G. Repetto, "Early phase fuel degradation in Phébus FP: Initiating phenomena of degradation in fuel bundle tests," Annals of Nuclear Energy, vol. 61, pp. 23-35, 2013.

[5] T. Haste, F. Payot, and P. D. W. Bottomley, "Transport and deposition in the Phébus FP circuit," Annals of Nuclear Energy, vol. 61, pp. 102-121, 2013.

[6] M. Laurie, P. March, B. Simondi-Teisseire, and F. Payot, "Containment behaviour in Phébus FP," Annals of Nuclear Energy, vol. 60, pp. 15-27, 2013.

[7] P. March and B. Simondi-Teisseire, "Overview of the facility and experiments performed in Phébus FP," Annals of Nuclear Energy, vol. 61, pp. 11-22, 2013.

[8] G. Brillant, C. Marchetto, and W. Plumecocq, "Fission product release from nuclear fuel II. Validation of ASTEC/ELSA on analytical and large scale experiments," Annals of Nuclear Energy, vol. 61, pp. 96-101, 2013.

[9] N. Hanniet-Girault and G. Repetto, FPT-0 Final Report, Institut de Radioprotection et de Sûreté Nucléaire, Saint-Paul-LesDurance, France.
[10] G. Gyenes and L. Ammirabile, "Containment analysis on the PHEBUS FPT-0, FPT-1 and FPT-2 experiments," Nuclear Engineering and Design, vol. 241, no. 3, pp. 854-864, 2011.

[11] K. Mueller, S. Dickinson, C. de Pascale et al., "Validation of severe accident codes on the phebus fission product tests in the framework of the PHEBEN-2 project," Nuclear Technology, vol. 163, no. 2, pp. 209-227, 2008.

[12] V. D. Layly, P. Spitz, S. Tirini, and A. Mailliat, "Analysis of the phebus FPT0 containment thermal hydraulics with the Jericho and Trio-VF codes," Nuclear Engineering and Design, vol. 166, no. 3, pp. 413-426, 1996.

[13] F. d. Rosa and R. Mari, "Thermal-hydraulics and physics near Phebus condenser, a comparison between codes and against some experimental data from FPT0 test," in Proceedings of the 7th International Conference on Nuclear Engineering (ICONE), Tokyo, Japan, 1999.

[14] A. Bujan, G. Gyenes, and H. Wider, Final Interpretation Report on the FPT0 and FPT1 Circuit and Containment Analyses, 2007.

[15] M. Di Giuli, T. Haste, R. Biehler et al., "SARNET benchmark on Phébus FPT3 integral experiment on core degradation and fission product behaviour," Annals of Nuclear Energy, vol. 93, pp. 65-82, 2016.

[16] B. Gonfiotti and S. Paci, "Stand-alone containment analysis of the Phébus FPT-1 test with the ASTEC and the MELCOR codes," in Proceedings of the 2016 24th International Conference on Nuclear Engineering, ICONE 2016, Charlotte, NC, USA, June 2016.

[17] A. Kontautas and E. Urbonavičius, "Analysis of aerosol deposition in PHEBUS containment during FPT-1 experiment," Nuclear Engineering and Design, vol. 239, no. 7, pp. 1267-1274, 2009.

[18] W. Klein-Hessling and B. Schwinges, ASTEC VO CPA Module Program Reference Manual, nstitut de Protection et de Surete Nucleaire (IPSN)/Gesellschaft fur Anlagen-und Reacktorsicherheit (GRS) mbH, 1998.

[19] L. Bosland, ASTEC V2.0 rev2 Code IODE Module: Iodine And Ruthenium Behaviour in The Containment, Institut de Protection et de Surete Nucleaire (IPSN)/Gesellschaft fur Anlagenund Reacktorsicherheit (GRS) mbH, Saint Paul-lez-Durance, France, 2011.

[20] G. Guillard, F. Jacq, C. Seropian, and W. Plumecocq, ASTEC V1 Code SYSINT Module Management of Events and Safety Systems Interactions, Institut de Protection et de Surete Nucleaire (IPSN)/Gesellschaft fur Anlagen-und Reacktorsicherheit (GRS) mbH, Saint Paul-lex-Durance, France, 2007.

[21] L. L. Humphries, R. K. Cole, D. L. Louie, V. G. Figueroa, and M. F. Young, MELCOR Computer Code Manuals Vol.1: Primer and User's Guide, Sandia National Laboratory, 2015.

[22] J. L. Tills, A. Notafrancesco, and J. Phillips, Application of the MELCOR Code to Design Basis PWR Large Dry Containment Analysis, Sandia National Laboratories, Albuquerque, NM, USA, 2009.

[23] D. S. Yoon, H. Jo, and M. L. Corradini, "Assessment of MELCOR condensation models with the presence of noncondensable gas in natural convection flow regime," Nuclear Engineering and Design, vol. 317, pp. 110-117, 2017.

[24] B. Gonfiotti and S. Paci, "A stand-alone containment analysis of the Phébus FPT- 0 test with the ASTEC and the MELCOR codes," in Proceedings of the 8th conference on Severe Accident Research, ERMSAR 2017, Warsaw, Poland, 2017.

[25] A. V. Jones, S. Dickinson, C. De Pascale et al., "Validation of severe accident codes against Phebus FP for plant applications: 
Status of the PHEBEN2 project," Nuclear Engineering and Design, vol. 221, no. 1-3, pp. 225-240, 2003.

[26] B. Clément, L. Cantrel, G. Ducros et al., "State of the Art Report on Iodine Chemistry," Tech. Rep., 2007.

[27] L. Soffer, S. Burson, C. Ferrell, R. Lee, and J. Ridgely, "Accident Source Terms for Light-Water Nuclear Power Plants," Tech. Rep., U.S. Nuclear Regulatory Commision, Washington, WA, USA, 1995.

[28] W. C. Hinds, Aerosol Technology, Wiley-Interscience Publication, 2012.

[29] E. Hontanon, J. Polo, and L. E. Herranz, "On the modelling capabilities to simulate aerosol behaviour in the PHEBUSFP containment: Lessons learned from FPT0 test," Journal of Aerosol Science, vol. 27, no. 1, pp. S459-S460, 1996.

[30] P. Dumaz and S. Cho, "Thermophoretic deposition in the first Phebus-FP experiment," Journal of Aerosol Science, vol. 26, pp. 83-84, 1996.

[31] A. Kontautas, E. Babilas, and E. Urbonavičius, "COCOSYS analysis for deposition of aerosols and fission products in PHEBUS FPT-2 containment," Nuclear Engineering and Design, vol. 247, pp. 160-167, 2012. 


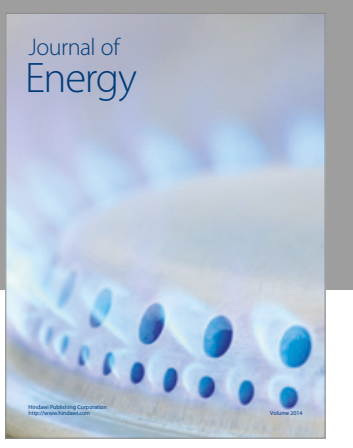

Journal of

Industrial Engineering
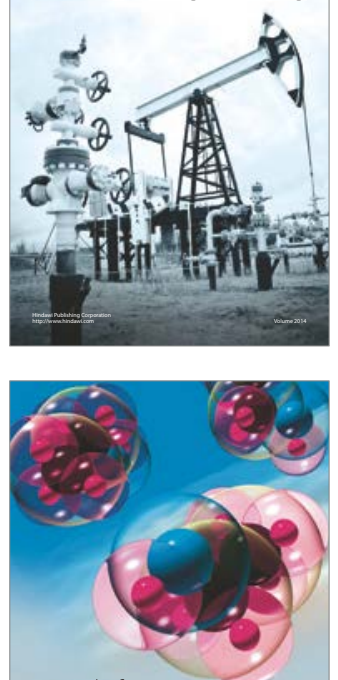

Fuels
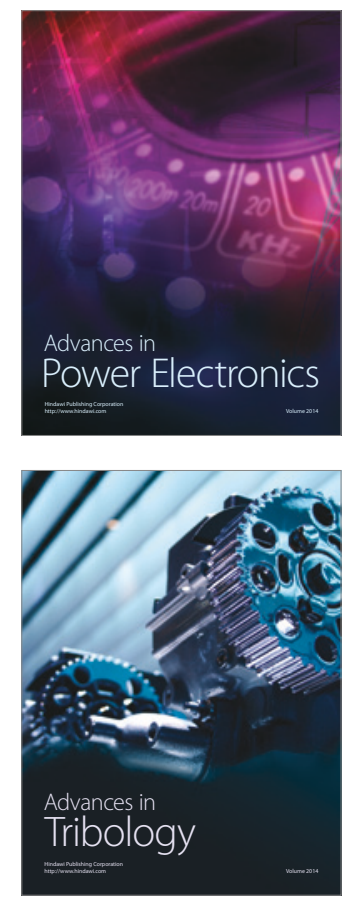
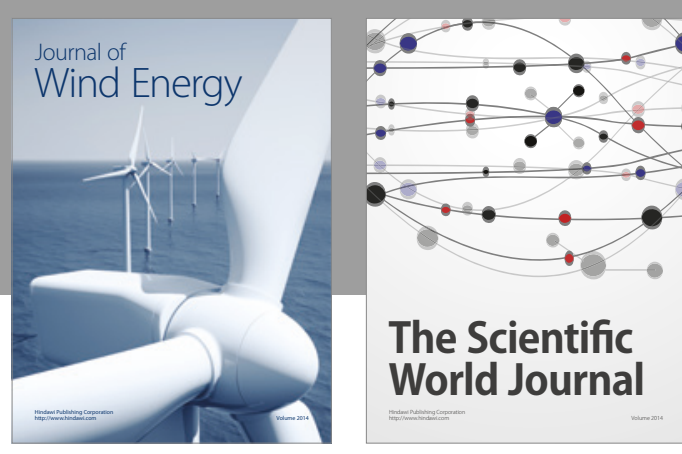

The Scientific World Journal
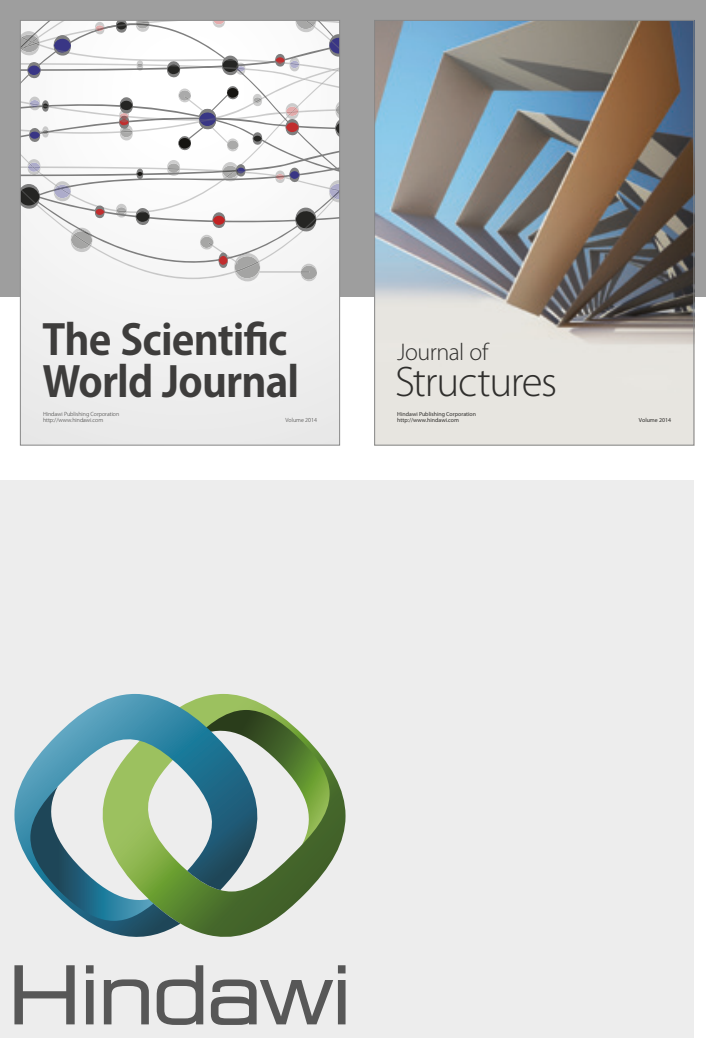

Submit your manuscripts at

https://www.hindawi.com
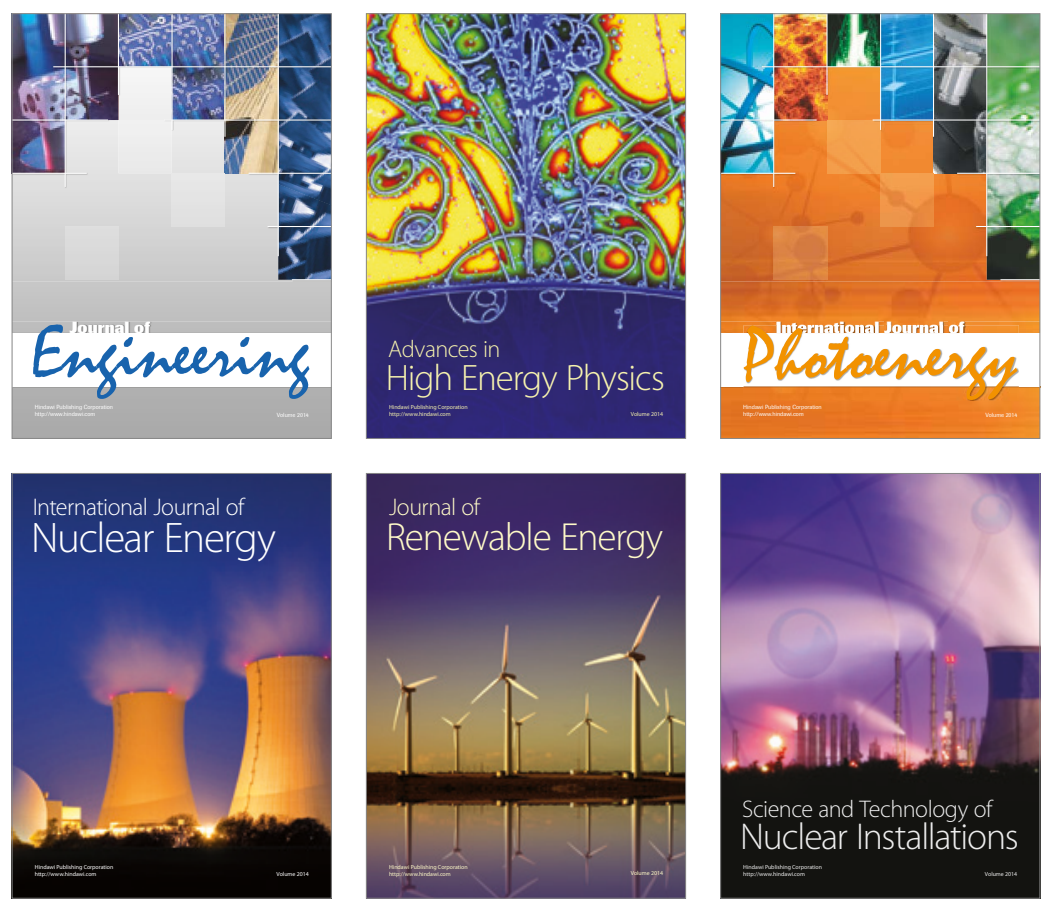

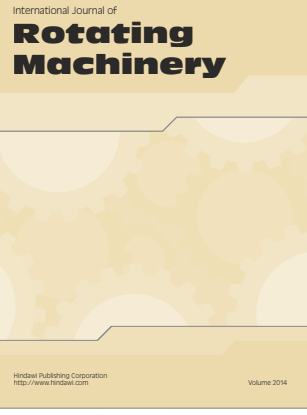

Journal of

Petroleum Engineering

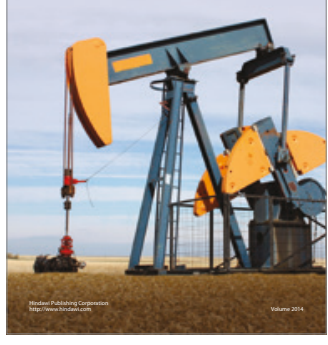

Journal of
Solar Energy
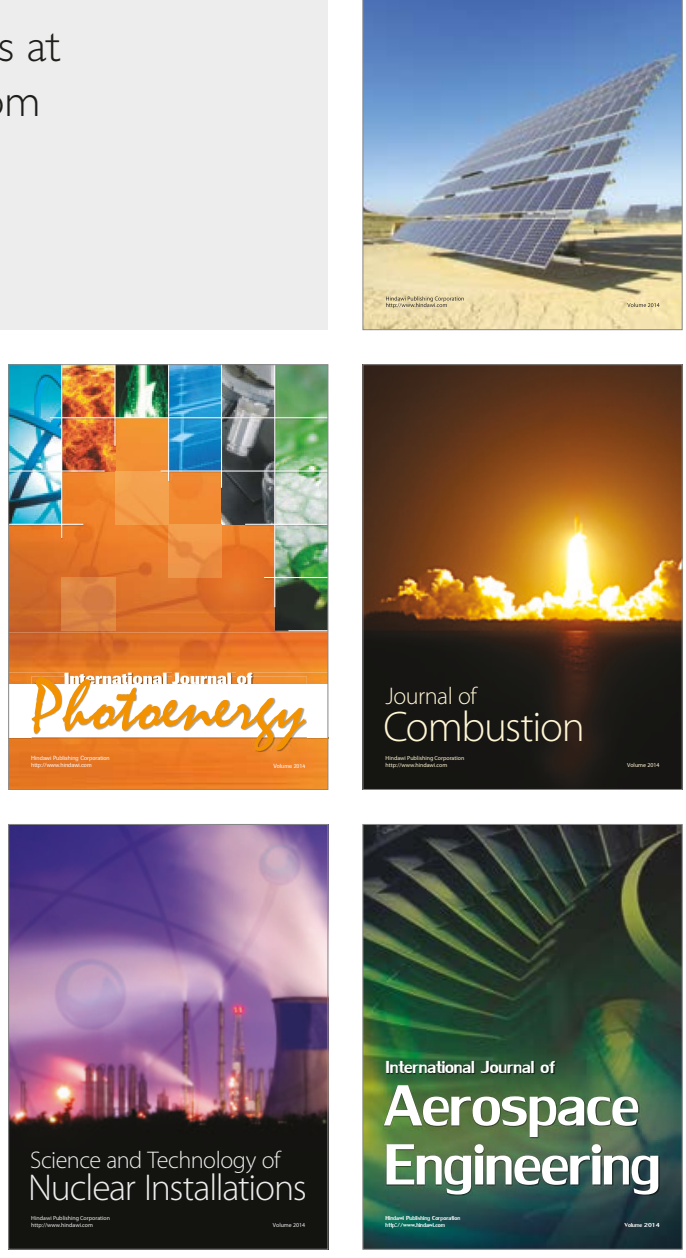